\title{
Numerical Study of Eastern Boundary Ventilation and Its Effects on the Thermocline Structure
}

\author{
Hiroshi Sumata And Atsushi Kubokawa \\ Graduate School of Environmental Earth Science, Hokkaido University, Sapporo, Japan
}

(Manuscript received 6 June 1999, in final form 13 March 2001)

\begin{abstract}
Numerical experiments with idealized OGCM are carried out to investigate the oceanic eastern boundary problems. The experimental results indicate that the eastward flow due to the north-south gradient of the surface density returns to the interior region through the lower half of the mixed layer, and this return flow generates a density jump just above the thermocline. Formulation for the mixed layer depth distribution at the eastern boundary is also presented, which is derived only from the geostrophy and no-normal flow condition. This formulation agrees well with the numerical experiment, and can be an appropriate eastern boundary condition for theoretical ventilated thermocline model with no deficiency of the mass balance on the boundary. Furthermore, the effects of such eastern boundary structure on the subtropical thermocline are studied. On the shallow thermocline in the subtropics, eastern boundary ventilated region emerges, which is identified as a region of high potential vorticity. In the deep thermocline, which does not outcrop in the subtropics, a cross-gyre ventilation occurs. This cross-gyre ventilation is caused by the density structure along the eastern boundary.
\end{abstract}

\section{Introduction}

Recent advances in the theoretical study of wind-driven oceanic circulation were started with the ventilated thermocline theory, presented by Luyten et al. (1983, hereafter LPS) and the theory of potential vorticity homogenization of unventilated thermocline (Rhines and Young 1982). In the LPS model, sea surface water particles in the subtropical gyre are pumped downward into the thermocline through subduction process. After subduction, water particles are isolated from direct effect of wind stress, and they retain their potential vorticity fixed at the outcrop position and are advected southward by Sverdrup flow. The three dimensional thermocline structure is determined by the potential vorticity distribution, whose isolines on the isopycnal surface coincide with the pathway of steady flow.

The LPS model divides subtropical interior region into three subdomains: the ventilated region where the subduction process determines the potential vorticity, a shadow zone where water is stagnant, and a pool region where signal propagates from the western boundary. Cox and Bryan (1984) carried out primitive equation numerical model experiments to simulate the circulation dynamics predicted by ventilated and unventilated thermocline theories. Talley (1985) also ap-

Corresponding author address: Mr. Hiroshi Sumata, Graduate School of Environmental Earth Science, Hokkaido University, N10 W5 Sapporo 060-0810, Japan.

E-mail: sum@ees.hokudai.ac.jp plied the LPS model to the north subtropical Pacific and successfully explained the observed shallow salinity minimum.

Although the LPS model successfully explained the maintenance mechanism of subtropical thermocline, there are two major deficiencies in the model: the model contains no mixed layer, and there are singularities along the eastern boundary. In the LPS model, no normal flow condition are applied on the eastern boundary. As a consequence of this assumption, all isopycnal surfaces which outcrop in the subtropical gyre must rise to the surface along the eastern boundary, that is, all ventilated layers have zero thickness along the eastern boundary.

Pedlosky (1983) first tried to improve the eastern boundary conditions of the LPS model. By assuming the existence of boundary layer near the eastern boundary where vertical exchange of water mass takes place, the stratification along the eastern boundary was specified and its effects on the interior thermocline was studied. Although Pedlosky (1983) clarified the eastern boundary problem in the LPS model and also showed that eastern boundary conditions have some effects on the thermocline structure, it is far from the solution of the problems.

De Szoeke (1992), using a layer model as in LPS (1983), studied the structure of oceanic circulation with alongshore wind stress near the eastern boundary. Since the model de Szoeke (1992) used contains no mixed layer, the model has to compensate the off-shore Ekman flux with the eastward flux in the thermocline. In this 
(a) schematics of model domain

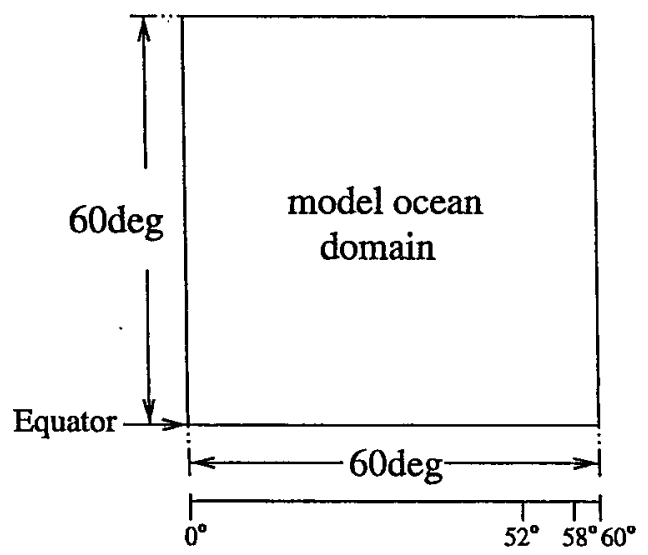

(A) (b) vertical grid spacing

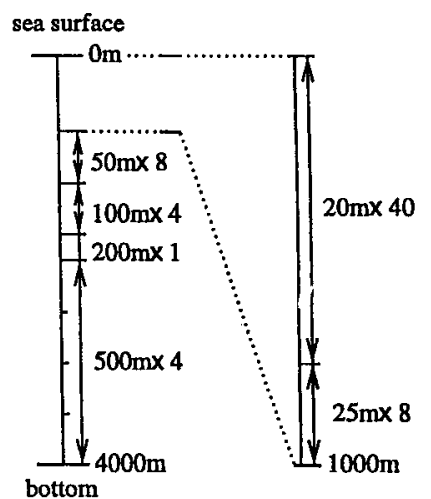

FIG. 1. The model configuration: (a) schematics of model domain and horizontal grid spacing and (b) vertical grid spacing. Grid spacing is uniform in the meridional direction. Longitudinal widths of grids are uniform $1^{\circ}$ in region $\mathrm{A}$, gradually reduce from $1^{\circ}$ to $0.2^{\circ}$ in region $\mathrm{B}$, and uniform $0.2^{\circ}$ in region $\mathrm{C}$. Thicknesses of vertical grids are $20 \mathrm{~m}$ at sea surface and $500 \mathrm{~m}$ at bottom of the model ocean.

multilayered model, it is impossible to know which layer supplies the water for westward flow in the upper Ekman layer, thus de Szoeke (1992) discussed several possible cases.

The ventilated thermocline model first presented by LPS (1983) has been improved in many subsequent papers. Pedlosky and Robbins (1991) presented a ventilated thermocline model in which a mixed layer of variable depth and density with latitude overlays the thermocline. By taking into account the mixed layer explicitly, the model becomes more realistic, that is, all ventilated layers have the eastern shadow zone, and the model realized more realistic eastern boundary stratification than the LPS model. However, considering the mixed layer in which depth and density continuously increase northward yields new deficiency - that is, eastward flow at the eastern boundary associated with the northward density gradient of the mixed layer emerged. Pedlosky and Robbins (1991) assumed that water mass exchange between the mixed layer and the uppermost adiabatic layer takes place along the boundary; however, the process of the exchange remains unclear.

Huang (1988) extended the LPS model to a continuously stratified model by using a density coordinate. As in the case of the layered models, the eastern boundary conditions are one of the major deficiencies in the model. To solve this problem, Huang (1989) proposed a no-net-zonal-flux condition on the eastern boundary instead of a no-normal-flow condition. As in Pedlosky (1983), Huang (1989) also predicted the possibility of the existence of the eastern boundary ventilated region of the subtropical gyre. The vertical exchange of water masses at the eastern boundary was also assumed and the definite physical process of such a diapycnal flow remained to be solved.
Although Huang (1988) contains no mixed layer, Huang (1990) extended it to a model that contains finite depth mixed layer and applied it to the North Atlantic Ocean circulation. The model successfully set up the stratification along the eastern boundary by considering the mixed layer, which has the finite and horizontally varying depth and a meridional density gradient. However, the eastward geostrophic flow associated with the density gradient in the mixed layer occurred at the eastern edge of the model region. Huang (1990) suggested that this eastward geostrophic flow at the eastern boundary could be compensated by a westward Ekman flow driven by the alongshore wind stress. In the case of North Atlantic, this eastward geostrophic flux seems to coincide with the westward Ekman flux near $35^{\circ} \mathrm{N}$. North of $35^{\circ} \mathrm{N}$, however, the eastward geostrophic flux in the mixed layer dominates, while the westward Ekman flux seems to be dominant in the south of $35^{\circ} \mathrm{N}$. Generally, the Ekman flux does not necessarily cancel out the eastward flux in the mixed layer at the eastern boundary. Huang (1990) also suggested that in the northern part of the subtropical gyre, a major part of the eastward geostrophic flow in the mixed layer might be cooled, sunk down, and come back into the interior as the eastern boundary ventilated thermocline. However, the model did not contain such a process explicitly. After Huang (1990), several papers using the ventilated thermocline model have been presented (see, e.g., Huang and Russel 1994; Kubokawa 1999). These papers, however, treated the eastern boundary condition in the same way as in Huang (1990).

Several studies with numerical experiments are also suggesting interesting results about this problem. Colin de Verdière (1989), using numerical model, discussed interaction of buoyancy and wind forcing. The model 
(b)
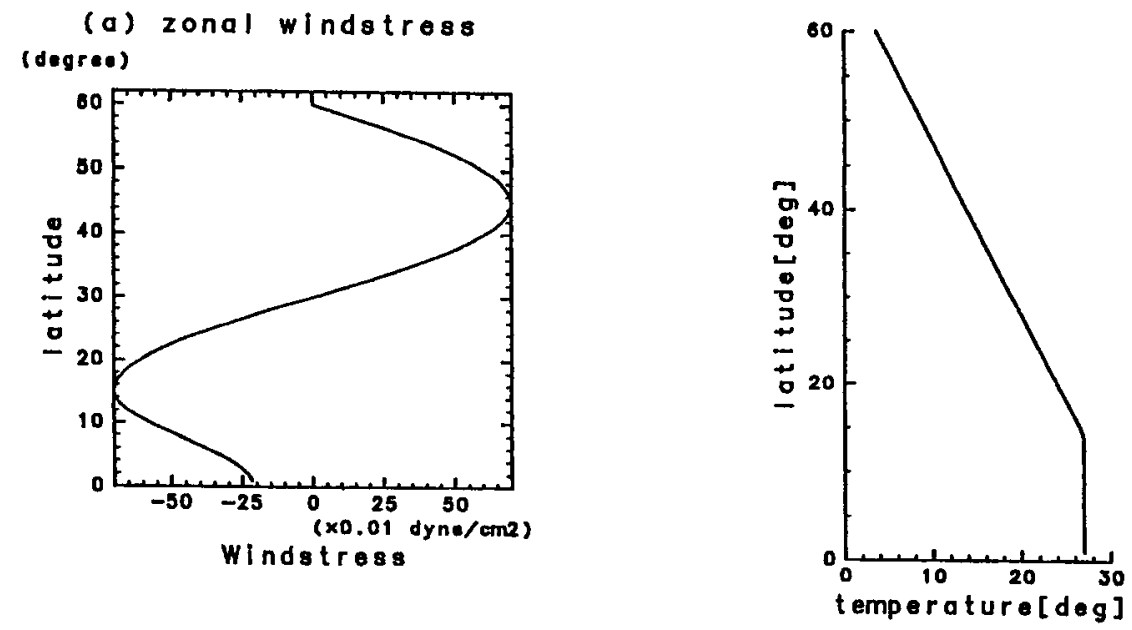

FIG. 2. (a) The meridional profiles of surface zonal wind stress $\tau_{\phi}$, and (b) the surface specific temperature $T_{a}$.

result shows that eastward flow that impinges eastern boundary downwells and it causes deep thermocline at the eastern boundary. In that paper, the author suggested the importance of diffusive mixing process at the eastern boundary which equilibrate the vertical advection. High potential vorticity water intrusion as a eastern boundary ventilation is also mentioned; however, the process of generation of such water and detailed structure of the eastern boundary remains unclear. Huck et al. (1999), also using a numerical model, pointed out that the high potential vorticity (PV) water injection from the northeastern corner of the model basin was controlled by the lateral boundary condition. They carried out experiments with several schemes to weaken the boundary ventilation.

Several papers with observational viewpoint are also presented. Arhan et al. (1994) studied the eastern boundary of North Atlantic, in which they discussed incoming and outflowing transport to the boundary. They suggested that the current crossing the bottom of sloping mixed layer was the main cause of ventilation of the eastern boundary. Paillet and Arhan (1996), using hydrographic data, studied North Atlantic eastern ventilation with an analytical model, in which they demonstrated that the large-scale stationary thermocline model

TABLE 1. Vertical and horizontal diffusion coefficients used in this study. (Units of these coefficients are $\mathrm{cm}^{2} \mathrm{~s}^{-1}$.)

\begin{tabular}{lccl}
\hline \hline & $\begin{array}{c}\text { Vertical } \\
\text { diffusion } \\
\left(K_{v}\right)\end{array}$ & $\begin{array}{c}\text { Horizontal } \\
\text { diffusion } \\
\left(K_{H}\right)\end{array}$ & $\begin{array}{c}\text { Eastern } \\
\text { boundary } \\
\text { condition }\end{array}$ \\
\hline Run 1 & 0.3 & $2.0 \times 10^{7}$ & No-slip \\
Run 2 & 0.1 & $2.0 \times 10^{7}$ & No-slip \\
Run 3 & 0.3 & $5.0 \times 10^{6}$ & No-slip \\
Run 4 & 0.3 & $2.0 \times 10^{6}$ & No-slip \\
Run 4s & 0.3 & $2.0 \times 10^{6}$ & Slip \\
\hline
\end{tabular}

could reproduce the essential features of the ventilation mechanism.

Although several realistic studies were presented, a theoretical model still cannot solve the eastern boundary structure of a simple basin. The purpose of this study is to investigate the eastern boundary structure of idealized ocean by using OGCM; furthermore, we explored the eastern boundary ventilation of numerical model and its effects on the subtropical thermocline structure. The remainder of this paper is organized as follows. In section 2, a description of the numerical model and parameters that used in this study is made. At the beginning of section 3, we show the numerical results focusing on the structure of the model eastern boundary, and then we discuss its dependency on each parameters. Afterward, as a limit of nondiffusivity, formulation for the eastern boundary structure of the idealized ocean is presented. In section 4, we show its effects on the subtropical thermocline structure. The results are summarized in section 5 .

\section{Model description}

In this study, we used Geophysical Fluid Dynamics Laboratory Modular Ocean Model (MOM Ver.1.1). This is called the Bryan-Cox model, and description of the schemes used in this model are detailed in Bryan (1969) and Cox and Bryan (1984).

This model solves the three-dimensional primitive equations in spherical coordinates. Hydrostatic and Boussinesq approximations are employed. A third-order polynomial approximation to the UNESCO (1981) is adopted for the equation of state of seawater.

\section{a. Model ocean and grid spacing}

In this experiment, we consider an idealized ocean, which contains no bottom topography, bounded by the 
equator and a $60^{\circ} \mathrm{N}$ latitudinal circle, and the longitudinal extent of this model is $60^{\circ}$ with the western boundary located at $0^{\circ}$. The uniform depth of the model ocean is $4000 \mathrm{~m}$.

The latitudinal resolution of the model is uniform and is $1^{\circ}$. In order to investigate the eastern-boundary structure, the model has high horizontal resolution near the eastern boundary; that is, in the longitudinal direction, there are three subdomains in terms of grid spacing. From the western boundary $\left(0^{\circ}\right)$ to $52^{\circ}$, longitudinal width of grids is uniform by $1^{\circ}$. From $52^{\circ}$ to $58^{\circ}$, grid spacing is not uniform and gradually reduces from $1^{\circ}$ to $0.2^{\circ}$. Near the eastern boundary, from $58^{\circ}$ to $60^{\circ}$, the width of grids is constant at $0.2^{\circ}$. The schematics of the model domain and horizontal grid spacing are given in Fig. 1a.

In the vertical direction, the model has 65 levels. The schematics of vertical grid spacing are also shown in Fig. 1b.

\section{b. Boundary conditions and model parameters}

The model ocean is driven by wind stress and heat flux through the sea surface. We used an idealized wind stress field in this experiment, which has zonal component only, made by referring to the global, annual mean, and zonally averaged wind stress of Hellerman and Rosenstein (1983). The wind stress $\tau$ is

$$
\begin{aligned}
\tau_{\lambda} & = \begin{cases}0.7 \times(0.35 \times \cos (12.0 \times \phi)-0.65) & \left(0^{\circ}<\phi \leq 15^{\circ}\right) \\
0.7 \times \cos (6.0 \times \phi+\pi / 2) & \left(15^{\circ} \leq \phi \leq 60^{\circ}\right)\end{cases} \\
\tau_{\phi} & =0,
\end{aligned}
$$

where $\lambda$ and $\phi$ represent longitudinal and latitudinal direction respectively. The distribution of the wind stress is shown in Fig. 2a.

The heat flux through the sea surface is assumed to have a Haney (1971)-type form:

$$
Q=\gamma\left(T_{a}-T_{s}\right),
$$

where $T_{s}$ is the sea surface temperature of the model ocean, and $\gamma$ is set to be a constant value at $100 \mathrm{~cm}^{-1 a y}{ }^{-1}$. Here, $T_{a}$ represents a specified atmospheric temperature, and is a function only of latitude, given by the following form:

$$
T_{a}= \begin{cases}27.0 & \left(0^{\circ}<\phi \leq 15^{\circ}\right) \\ -\phi \times(23.0 / 45.0)-(103.0 / 3.0) & \left(15^{\circ} \leq \phi \leq 60^{\circ}\right),\end{cases}
$$

where $\phi$ represents latitude. The meridional distribution is shown in Fig. $2 b$.

Except for the sea surface, the model ocean boundary is insulated thermally. A no-slip condition is applied to the model lateral walls, and a free slip condition is applied to the bottom boundary.

The coefficients of horizontal eddy viscosity $A_{H}$ and the vertical eddy viscosity $A_{V}$ are

$$
A_{H}=1.0 \times 10^{8} \mathrm{~cm}^{2} \mathrm{~s}^{-1}, \quad A_{V}=1.0 \mathrm{~cm}^{2} \mathrm{~s}^{-1},
$$

respectively. On the other hand, in order to investigate the effects of horizontal and vertical diffusion, we carried out four cases with different horizontal and vertical eddy diffusion coefficients (shown in Table 1). When the density structure is statically unstable, the vertical diffusivity and viscosity are set at $1.0 \times 10^{6} \mathrm{~cm}^{2} \mathrm{~s}^{-1}$, which is the convective adjustment in this model.

In addition to the above experiments, we also carried out an experiment in which the slippery condition is applied to the eastern boundary (run 4s).

\section{c. Initial conditions and Integration}

The model ocean is initially at rest and the stratification is zonally uniform. The initial temperature field is based on the zonally averaged climatological mean temperature (Levitus 1982). The salinity field of the model ocean is set to be constant value of $34.9 \mathrm{psu}$. The time step is $15 \mathrm{~min}$.

After 40-yr integration, the model ocean reached a quasi-steady state except for the abyssal part. The quasi steadiness was checked by comparing the data of the $40-y r$ integration and those of 50-yr integration. In runs 2 and 3, the integration is started from the 20th year of data in run 1 . We analyze the $1-y r$ averaged data at the 40th year.

\section{Ocean structure near the eastern boundary}

\section{a. Numerical results}

Figure 3 shows a barotropic stream function of run 1. There are three gyres in the model basin: subpolar, 


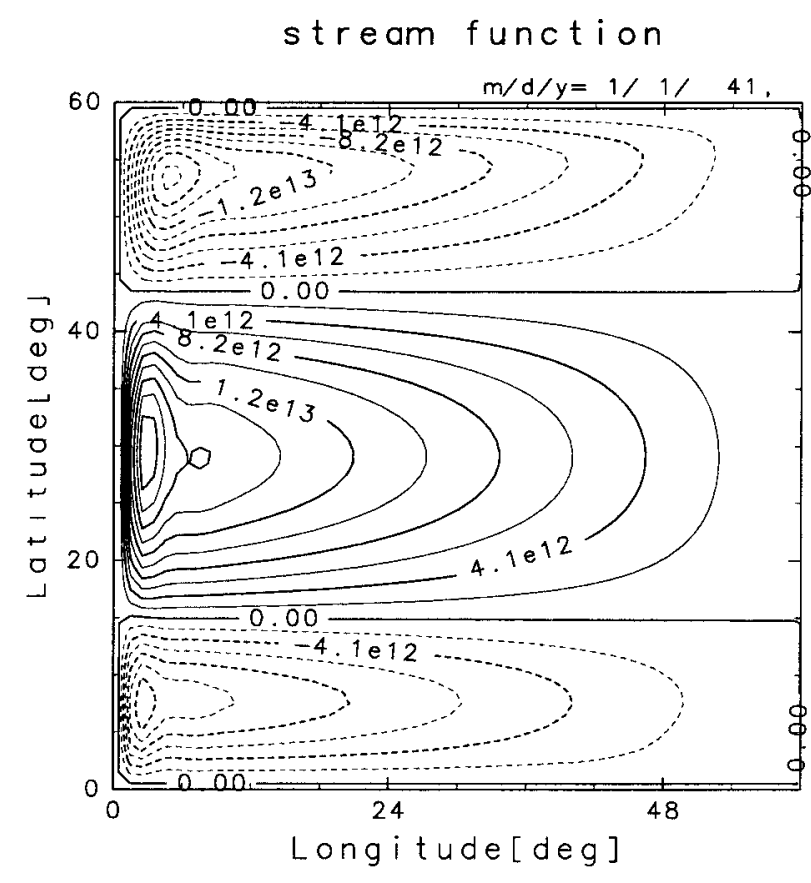

FIG. 3. Barotropic stream function of standard case; run $1\left(K_{V}=\right.$ $\left.0.3, K_{H}=2.0 \times 10^{7}\right)$. Contour unit is $\left(\mathrm{cm}^{3} \mathrm{~s}^{-1}\right)$. Total meridional transport and barotropic velocity except for the western boundary agree well with the Sverdrup Balance.

subtropical, and tropical, each of which has the western boundary current. The barotropic field resembles the classical linear theory, suggesting that the Sverdrup balance gives a good approximation except for the western boundary. The intergyre boundary (hereafter IGB) between subpolar and subtropical gyre is about $43.5^{\circ} \mathrm{N}$, consistent with the classical Sverdrup theory using the wind stress field given by (2.1). Figure 4 shows the density distribution on the meridional section (longitude $\left.=30.5^{\circ}\right)$. In the subtropical gyre from $15^{\circ}$ to $43^{\circ} \mathrm{N}$, the isopycnal surface is deepening in the center of the gyre and it produces clockwise circulation. Such a density structure is common to the Pacific or the Atlantic Oceans, and it is also consistent with the prediction of the theoretical ventilated thermocline model. The dashed line in Fig. 4 indicates the depth where the density is $0.1 \sigma_{\theta}$ heavier than that at the sea surface. Hereafter, we use this depth as the mixed layer depth of the model. It should be noted here that the mixed layer is deep in the northern half of the model domain.

Let us begin our analysis of the eastern boundary density structure by considering the implications of idealized theoretical models. If the no-normal flow condition is applied below the mixed layer at the eastern boundary, the isopycnal surface in the thermocline must be level in the meridional direction. Under such conditions, northward density gradient in the mixed layer adjacent to the eastern boundary causes the eastward water mass transport. This is because the zonal velocity at the bottom of the mixed layer is zero and eastward

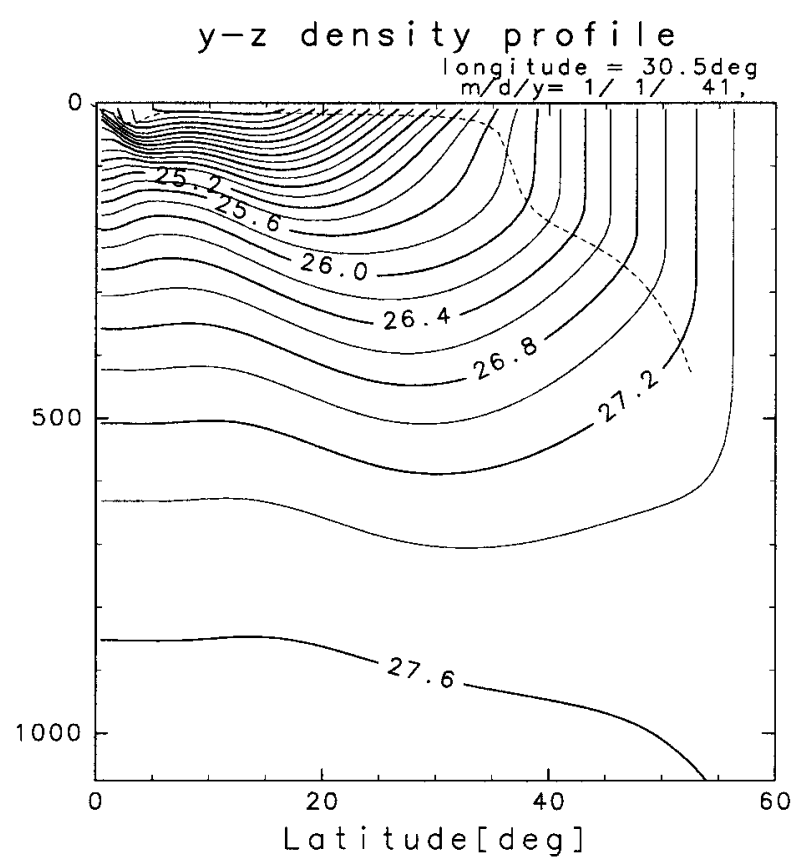

FIG. 4. Density distribution in a meridional section of run 1 (longitude $=30.5^{\circ}$ ). Dashed line indicates bottom of mixed layer, which is defined as the depth where the density difference from the sea surface value is $0.1 \sigma$.

velocity linearly increases in the vertical direction due to the northward density gradient. Therefore, the net mass flux cannot vanish. One of our primary objects is to clarify this contradiction of mass balance at the eastern boundary.

Figure 5 depicts the meridional section of the density near the eastern boundary (longitude $=59^{\circ}$ ), and shows that the isopycnal surfaces in the thermocline near the eastern boundary are not smoothly connected to the bottom of the mixed layer-but it deepens steeply once, and then connects to the bottom of the mixed layer. Figure 6 shows the zonal velocity on the same section. Westward flow exists near the bottom of the mixed layer, which compensates the eastward flow in the upper half of the mixed layer. As shown in appendix A, the eastward flow in the upper part of the mixed layer sinks down within a few grid points adjacent to the boundary, and then it returns to the interior region below the eastward flow. Since the meridional velocity is small even near the eastern boundary (see appendix B), the water particle coming from the west sinks down almost without meridional excursion, and hence the density of the return flow is almost the same as that in the surface eastward flow. We checked the zonal flow near the eastern boundary (longitude $=59^{\circ}$ ) of the model, and it was shown that the vertically integrated zonal flow was almost zero at each latitude. Vertically integrated nonet zonal flux condition in this model is consistent with the inclined isopycnals shown in Fig. 5. Furthermore, we can easily imagine this westward flow that emanates 


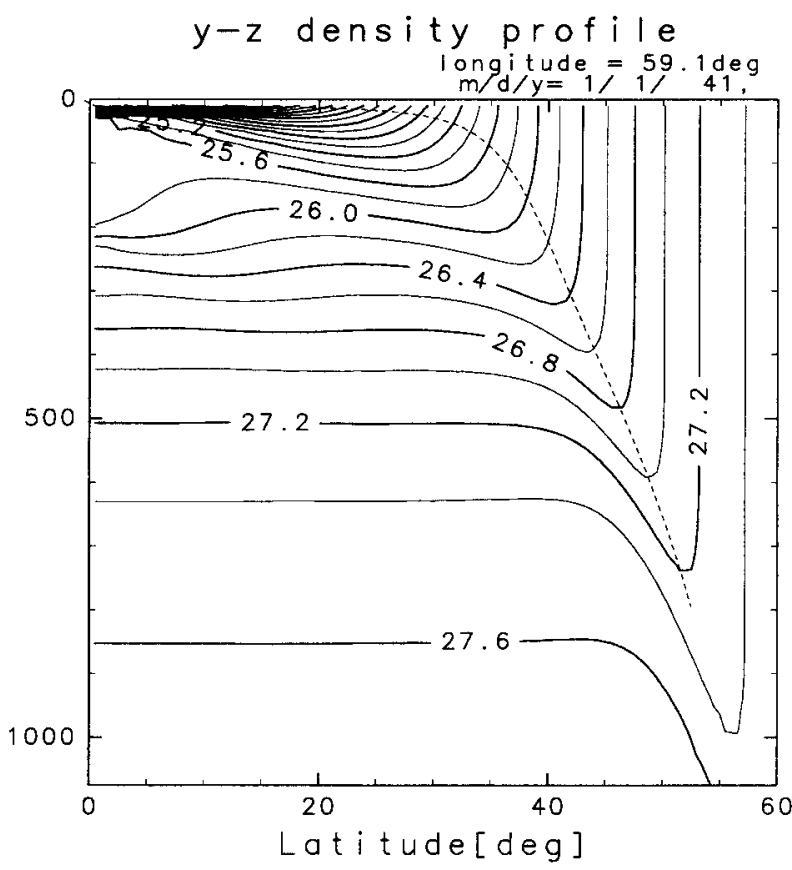

FIG. 5. Same as Fig. 4, but near the eastern boundary. (Longitude $=59.1^{\circ}$.)

from the boundary will affect on the interior thermocline structure.

Figure 7 shows the geostrophic zonal velocity on the same section as in Fig. 6. The geostrophic velocity is obtained by integrating the meridional density gradient from the bottom, where the model result velocity is assumed in geostrophic balance. These figures clearly prove that except for the upper part of the mixed layer, the zonal velocity on the meridional section near the eastern boundary is almost geostrophic, suggesting that the convection is not active in the lower half of the mixed layer. As shown in appendix A, the strong vertical velocity is limited in narrow boundary region, hence the vertical velocity at $59^{\circ}$ is weak and hardly affects the geostrophic balance on this section. Of course, such geostrophic balance cannot be held at the boundary because the eastern wall block the zonal flow. However, the zonal velocity $1^{\circ}$ apart from the boundary is in geostrophic balance. Momentum balance along the eastern wall is detailed in appendix B.

In the upper part of the subpolar region, zonal velocity is vertically homogenized, while the zonal velocity is almost geostrophic in the subtropical region. If the period that the convective adjustment occurs is much less than the inertial period, the horizontal velcotiy is vertically homogenized, but if it is much longer than the inertial period, the geostrophic adjustment leads to geostrophic balance. We can see the surface zonal jet around the IGB where the strength of convection seems to be medium range of upper subpolar region and the subtropics. We guess that the frequency of the convective adjustment in this region is comparable to inertial pe-

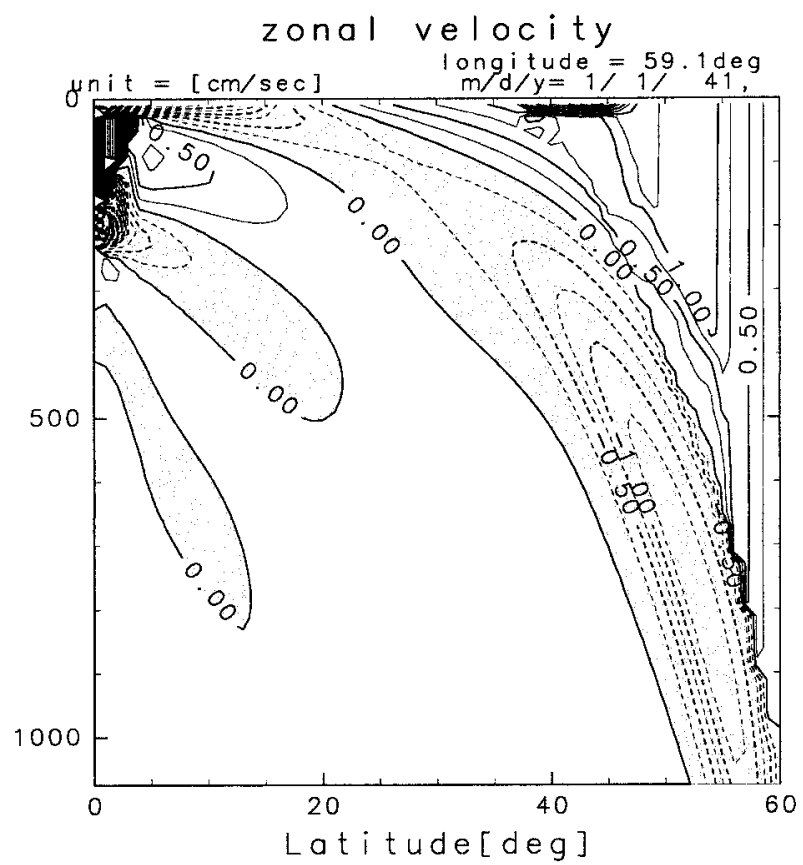

FIG. 6. Zonal velocity distribution in a meridional section near the eastern boundary (Longitude $=59.1^{\circ}$.) Shaded region denotes westward flow.

riod, and this zonal jet is a kind of unsteady Ekman flow (see, e.g., Gill 1982, chapter 9.3). Although the zonal velocity in the upper part of the mixed layer is not in geostrophic balance, vertically integrated zonal flux coincides with the geostrophic calculation, which is shown in the next subsection.

In order to investigate the effects of diffusion coefficients on the eastern boundary structure, we carried out three additional experiments. Figure 8 shows density fields in the same meridional section, with various horizontal-vertical diffusion coefficients. Figures 8a-d correspond to runs 1-4, respectively. Solid line indicates the isopycnal surface and dashed line indicates the bottom of the mixed layer, where the density is heavier at 0.1 in $\sigma_{\theta}$ than the sea surface density. Comparing Figs. $8 \mathrm{~b}$ and $8 \mathrm{a}$, we find that the reduction of the vertical diffusion coefficient leads to a cooling of the thermocline because the vertical heat transport is weakened and as a result, the mixed layer depth is somewhat shallower. However, the density profile around the mixed layer bottom is not very sensitive to the vertical diffusion. On the other hand, Figs. $8 \mathrm{c}$ and $8 \mathrm{~d}$ indicate the importance of the horizontal diffusion in determining the density structure. When the horizontal diffusion coefficient is small, the density jump at the bottom of the mixed layer is sharp.

Figure 9 shows the meridional section of zonal velocity at the same longitude as in Fig. 8. Similar to the density field, the velocity field does not depend strongly on the vertical diffusion as shown in Figs. 9a and 9b. On the other hand, the weak horizontal diffusion, as in 


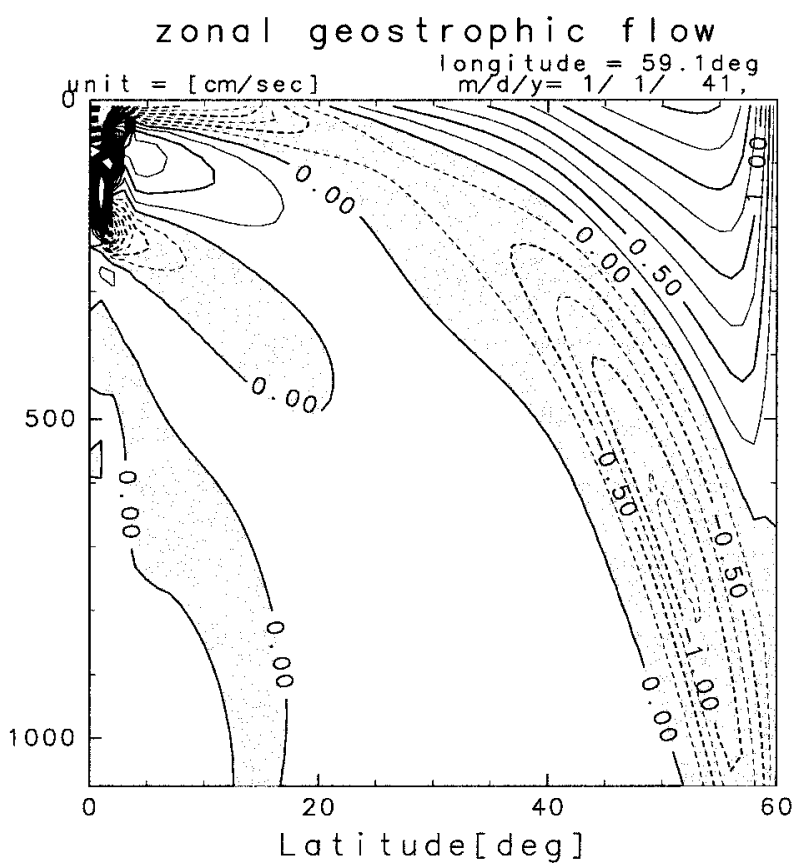

Fig. 7. Same as Fig. 6, but for the zonal geostrophic velocity.

Figs. 9c and 9d, yields strong vertical shear of the zonal velocity around the bottom of the mixed layer, and the zonal velocity is confined within the mixed layer.

In addition to the above parameter study, we also carried out an experiment in which the slippery condition is applied to the eastern boundary (run 4s). In that case, we obtained the almost same density structure as that in run 4 . This denotes the structure is insensitive to the lateral wall boundary condition as well, at least, in the present model resolution.

\section{b. Theoretical model}

It has been shown that the zonal flow at the eastern boundary return within the mixed layer in the limit of small diffusion. In this section, we consider what shape of density structure is needed when the zonal flow is limited in the mixed layer.

Let us begin our formulation by considering the geostrophic transport in the mixed layer. In the upper half of the mixed layer, the vertical mixing coefficient is very large because of static instability, so that the velocity field there is not geostrophic. Even in such a situation, if the vertical eddy viscosity $A_{V}$ and its derivative vanishes at the bottom of the mixed layer, the vertically integrated zonal transport in the mixed layer can be represented by the geostrophic one.

In the mixed layer, the vertical shear of the zonal flow can be written as

$$
\frac{\partial u}{\partial z}=\frac{g}{\rho_{0} f} \frac{\partial \rho_{s}}{\partial y}+\frac{1}{f} \frac{\partial^{2}}{\partial z^{2}} A_{V} \frac{\partial v}{\partial z},
$$

where $\rho_{s}$ represents the density at the sea surface, other variables here denote traditional meanings, and $y$ is the meridional coordinate. In integration of (3.6) yields the zonal velocity in the mixed layer,

$$
\begin{aligned}
u(z)= & \left.u\right|_{z=z_{m}}+\frac{g}{\rho_{0} f} \frac{\partial \rho_{s}}{\partial y}\left(z-z_{m}\right) \\
& +\frac{1}{f}\left[\frac{\partial}{\partial z} A_{V} \frac{\partial v}{\partial z}\right]_{z=z_{m}}^{z},
\end{aligned}
$$

where $z_{m}$ represents depth of the mixed layer. Since the geostrophic balance holds in the lower half of the mixed layer, we can assume that $A_{V}=\partial A_{V} / \partial z=0$ at $z=z_{m}$. The vertically integrated zonal flux in the mixed layer at each latitude can be written as

$$
U=\int_{z_{m}}^{0} u(z) d z=-\left.z_{m} u\right|_{z=z_{m}}+\frac{g}{\rho_{0} f} \frac{\partial \rho_{s}}{\partial y} \frac{z_{m}^{2}}{2},
$$

if we neglect the meridional wind stress $\tau_{\phi}=\rho A_{v} \partial v /$ $\left.\partial z\right|_{z=0}$ as in our idealized OGCM. Assuming that the eastward current in the upper half of the mixed layer returns westward in the lower half-that is, $U=0$ we get

$$
\left.u\right|_{z=z_{m}}=\frac{g}{\rho_{0} f} \frac{\partial \rho_{s}}{\partial y} \frac{z_{m}}{2} .
$$

In order to determine the meridional distribution of the mixed layer depth, we introduce the density coordinate and Bernoulli function defined as

$$
B=P+\rho g z .
$$

The geostrophic and the hydrostatic equations are

$$
\begin{aligned}
u & =-\frac{1}{\rho_{0} f} \frac{\partial B}{\partial y}, \\
\frac{\partial B}{\partial \rho} & =g z .
\end{aligned}
$$

From these equations, the thermal wind relation in the density coordinate can be written as

$$
\frac{\partial u}{\partial \rho}=-\frac{g}{\rho_{0} f} \frac{\partial z}{\partial y} .
$$

Now we write the density jump at $z=z_{m}$ as $\Delta \rho$. Since the zonal velocity in the thermocline is zero in the vicinity of the eastern boundary, integration of (3.13) from $\rho=\rho_{s}+\Delta \rho$ to $\rho=\rho_{s}$ yields

$$
\left.u\right|_{z=z_{m}}=\frac{g}{\rho_{0} f} \frac{\partial z_{m}}{\partial y} \Delta \rho .
$$

Since the basic stratification below the mixed layer is independent of the latitude, we can write the density there as $\rho=\rho_{A}(z)$. We assume that $\rho_{A}(z)$ is a given function of $z$. Using $\rho_{A}$, the density jump at $z=z_{m}$ can be represented by 

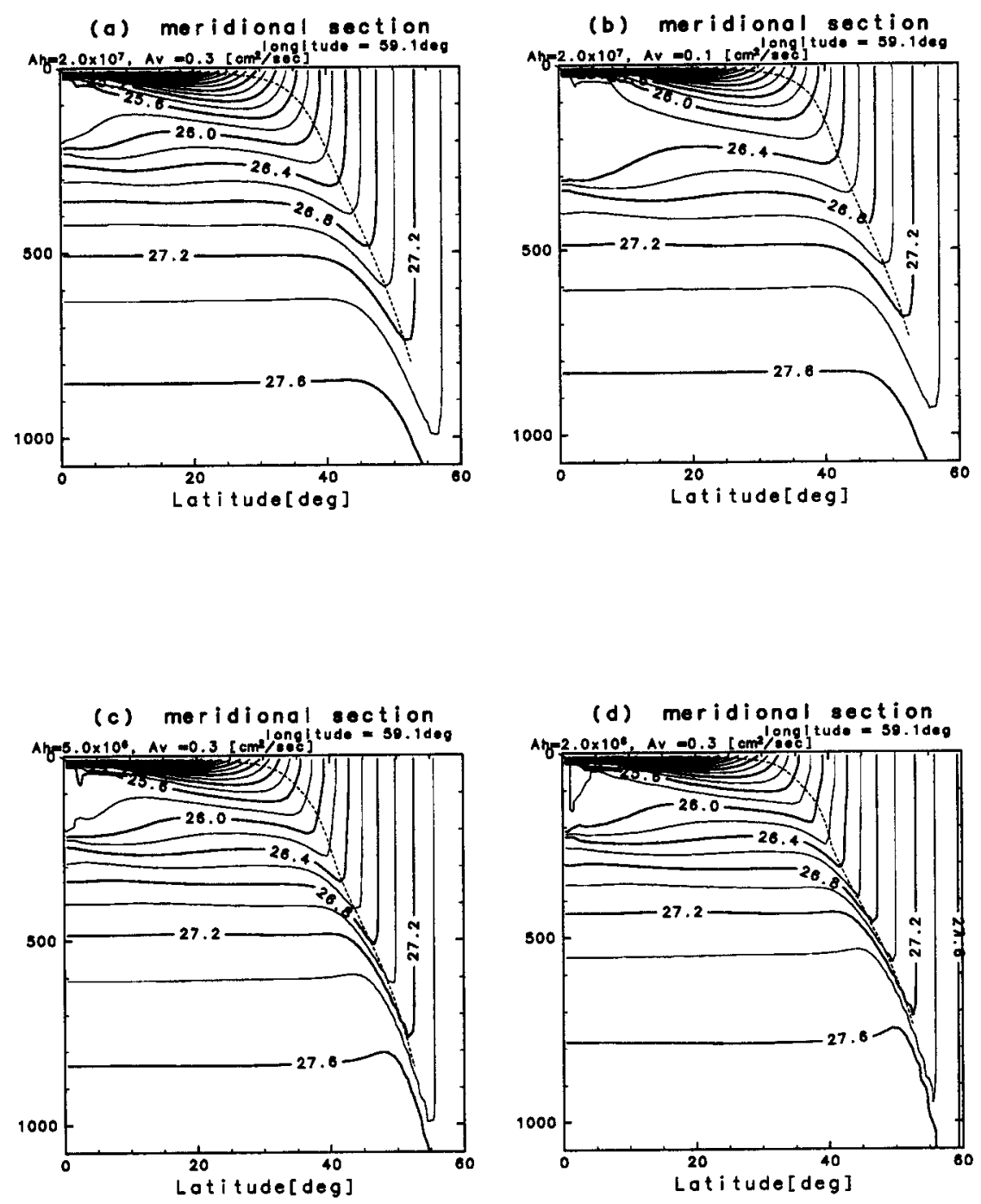

FIG. 8. Density distribution in a meridional section near the eastern boundary (longitude $=$ $59.1^{\circ}$ ): (a) run 1 , (b) run 2 , (c) run 3 , and (d) run 4 . Dashed line indicates bottom of the mixed layer.

$$
\Delta \rho=\rho_{A}\left(z_{m}\right)-\rho_{s} .
$$

Finally, (3.9), (3.14), and (3.15) give the relationship among the depth of mixed layer, the sea surface density, and the basic stratification, respectively. That is,

$$
\frac{\partial z_{m}}{\partial y}=\frac{\partial \rho_{s}}{\partial y} \frac{z_{m}}{2} \frac{1}{\rho_{A}\left(z_{m}\right)-\rho_{s}} .
$$

In another form,

$$
\frac{\partial z_{m}}{\partial \rho_{s}}=\frac{z_{m}}{2} \frac{1}{\rho_{A}\left(z_{m}\right)-\rho_{s}} .
$$

This equation means that in the vicinity of the eastern boundary, the meridional gradient of the mixed layer depth is determined by the sea surface density and the basic stratification of the thermocline. If we specify the mixed layer depth near the eastern boundary at the arbitrary latitude, the mixed layer depth along the eastern boundary can be derived by the above equation.

Figure 10 shows the mixed layer depth along the eastern boundary calculated by (3.16). The calculation of the mixed layer depth starts from $33.5^{\circ} \mathrm{N}$ where the mixed layer depth is given. The distribution of the sea surface density obtained by the model results is used as $\rho_{s}$, and the basic stratification $\rho_{A}(z)$ is determined by the experimental value at $33.5^{\circ} \mathrm{N}$. Figures $10 \mathrm{a}$ and $10 \mathrm{~b}$ represent the case with $K_{H}=2.0 \times 10^{7}$ and $K_{H}=2.0$ $\times 10^{6}$, respectively. In the case of large horizontal diffusion coefficient (Fig. 10a), there are some discrepancies between the mixed-layer depth obtained by (3.16) and that of model output. On the other hand, the case of small horizontal diffusion coefficient (Fig. 10b) shows good agreement between the calculation and the 

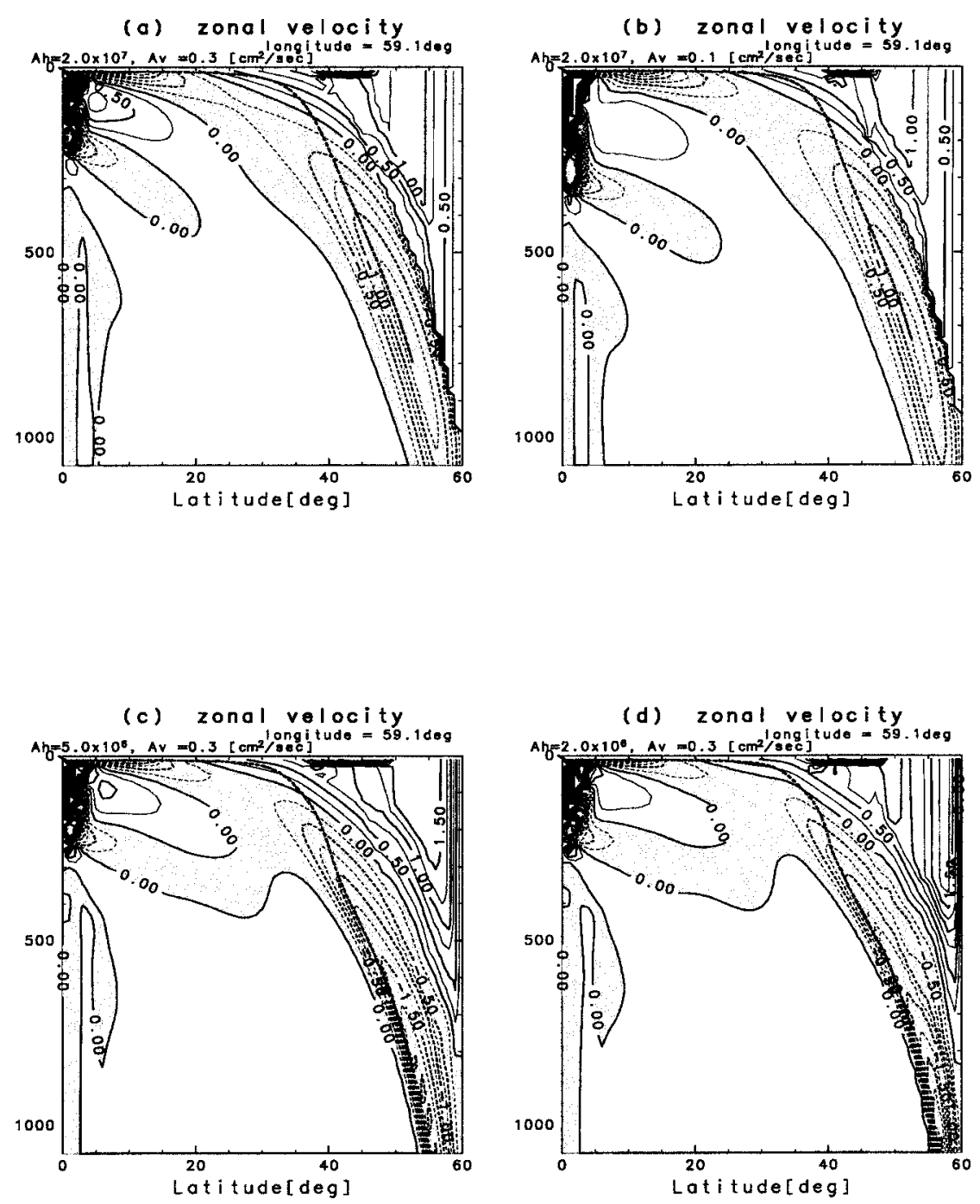

FIG. 9. Zonal velocity distribution in a meridional section near the eastern boundary (longitude $=59.1^{\circ}$ ): (a) run 1 , (b) run 2 , (c) run 3 , and (d) run 4 . Contour intervals are $0.25 \mathrm{~cm} \mathrm{~s}^{-1}$, shaded regions denote westward velocity, bold dashed lines indicate bottom of the mixed layer.

model output. This result suggests that the mixed layer depth along the eastern boundary is simply determined by the no-normal-flow condition and meridional gradient of the surface density at least when the horizontal diffusion is small.

\section{Effect of the eastern boundary on the interior region}

In this section, we will examine how such an eastern boundary structure as described in the previous section affects the interior thermocline structure.

Figure 11 shows the zonal section of the density and meridional velocity at $38.5^{\circ} \mathrm{N}$ of run 4 . Figure 11 a shows that the shallow isopycnal surfaces (e.g., $26.0<\sigma_{\theta}<$ 26.4) deepen steeply eastward near the eastern boundary, and as a consequence of this inclined isopycnal surface, northward flow exists beneath the surface Ekman layer (Fig. 11b). On the other hand, deep isopycnal surfaces near the eastern boundary rise eastward, causing southward undercurrent. The reason why these structures are trapped by the eastern boundary is that the Sverdrup dynamics limit them to the east of the ventilated region or recirculation region (For the lateral distributions, see Figs. 14 and 15.)

Figure 12 shows the zonal section of the density and meridional velocity at $43.5^{\circ} \mathrm{N}$, that is, the zonal section at the intergyre boundary of run 4 . In the same way as in Fig. 11a, the shallow isopycnal surfaces deepen steeply eastward, while the deep isopycnals rise eastward. Northward alongshore flow beneath the surface Ekman layer and the southward undercurrent also exist, which indicates that the density jump along the eastern boundary causes the cross-gyre flow at the IGB. As mentioned 


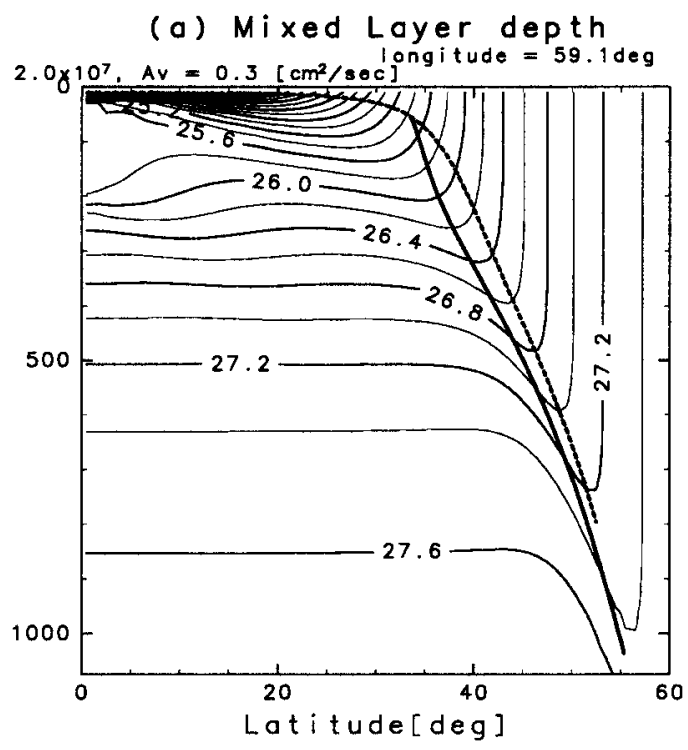

(b) Mixed Layer depth

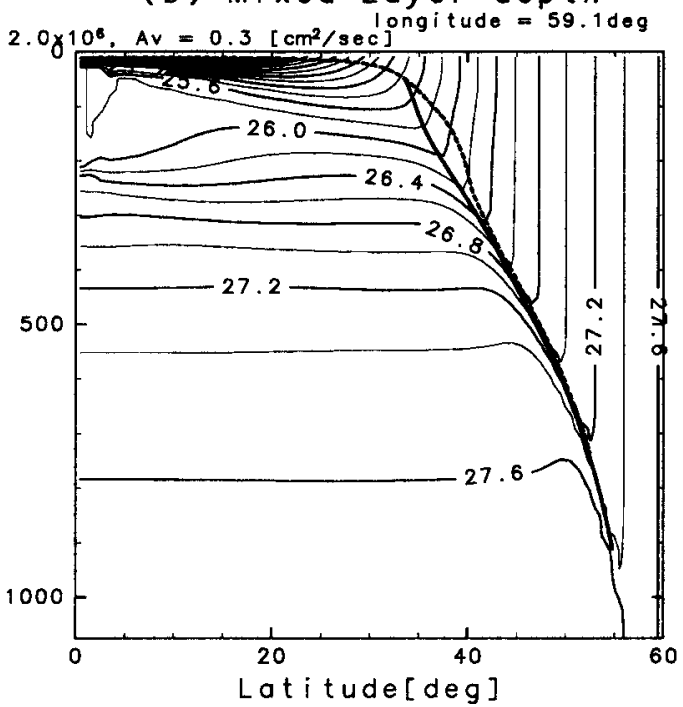

FIG. 10. Mixed layer depth with density distribution in the meridional section near the eastern boundary (longitude $=59.1^{\circ}$ ). Dashed line denotes model output mixed layer depth, and bold solid line denotes mixed layer depth calculated by Eq. (3.16): (a) run 1, in which $K_{H}=2.0 \times 10^{7}$; (b) run 2 , in which $K_{H}=2.0 \times 10^{6}$.

in the previous section, the Sverdrup balance gives a good approximation, therefore, the vertically integrated meridional flux of these alongshore flow cancel out at the IGB, so that the cross-gyre flow has a baroclinic structure (e.g., Pedlosky 1984). A similar structure of the density and the meridional current can be seen from the northern part of the subtropical gyre to the subpolar gyre. The deepening of the shallow isopycnals near the eastern boundary is caused by the deepening of the mixed layer. The shallowing of the deeper isopycnals is the consequence of the isostasy ensuring that the abys-
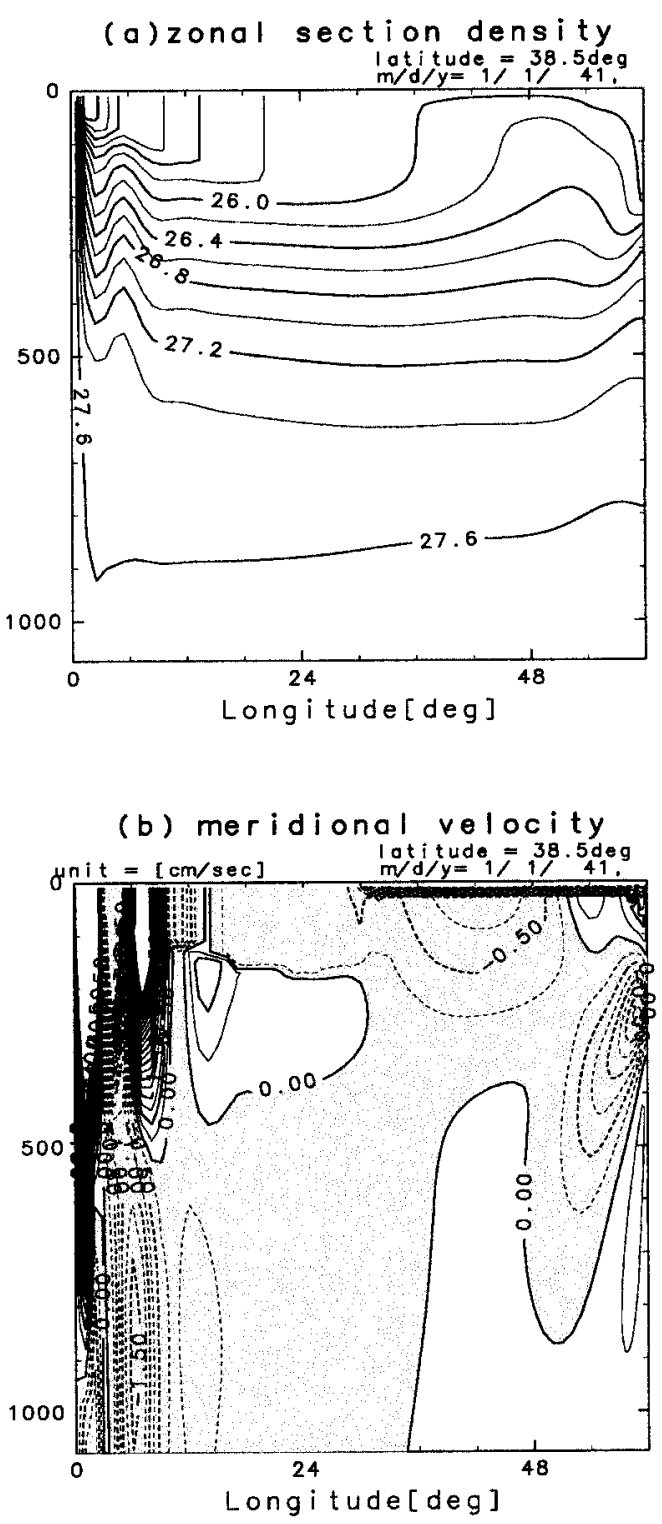

FIG. 11. Zonal section in the northern part of the subtropical gyre (run 4), latitude $=38.5^{\circ}$ : (a) the density structure, in which the contour line indicates the isopycnal surface; and (b) the zonal velocity on the same section, in which the shaded region indicates the southward flow and the contour interval is $0.25 \mathrm{~cm} \mathrm{~s}^{-1}$.

sal water is almost at rest. The strength of the meridional current must depend on the jump between the mixed layer depth in the open ocean and that along the eastern boundary. Since the mixed layer in the eastern half of the subpolar gyre is deep, the meridional current along the eastern boundary is weak in the northern subpolar gyre.

Figure 13 shows the potential vorticity and the Bernoulli function on the isopycnal surface of $\sigma_{\theta}=26.0$. This isopycnal surface outcrops at $40^{\circ} \mathrm{N}$, the northern part of the subtropical gyre. Large closed contour of Bernoulli function in the center of the subtropical gyre 


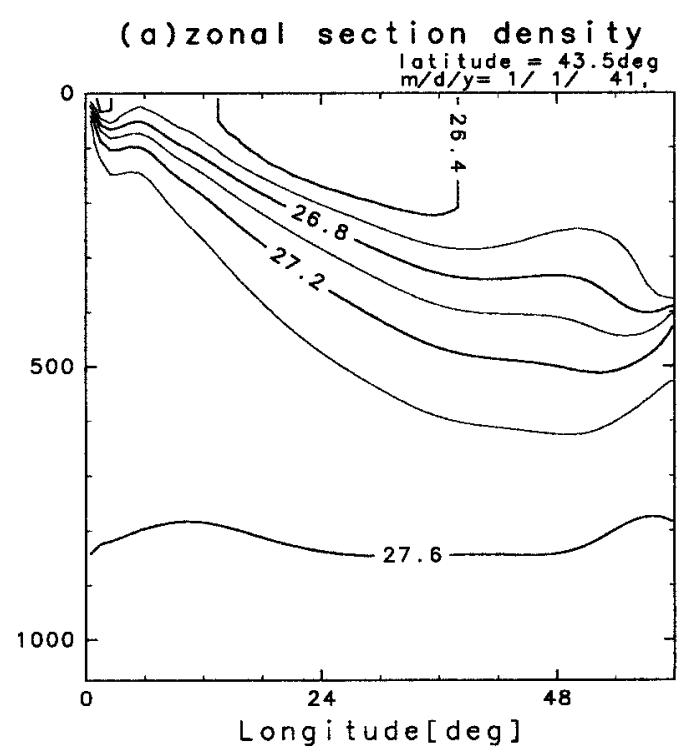

(b) meridional velocity

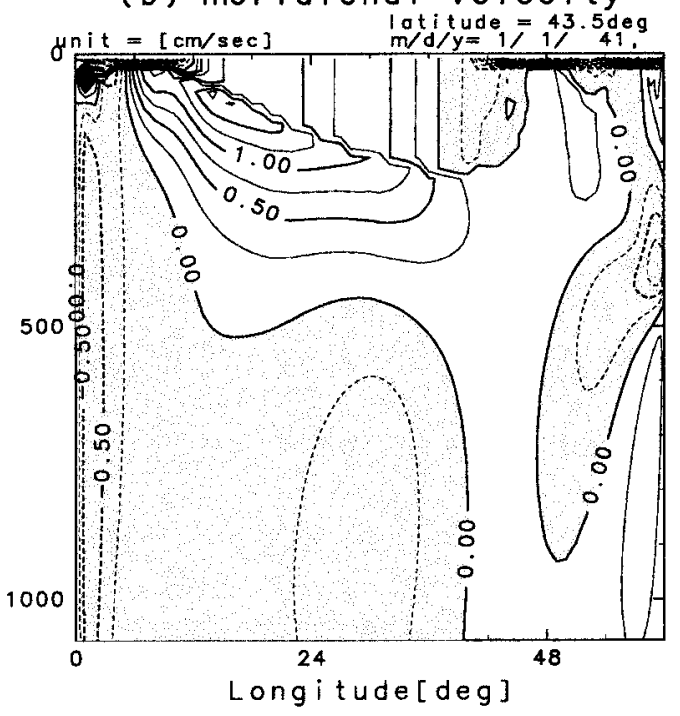

FIG. 12. Same as Fig. 11, but at the intergyre boundary (latitude $=$ $\left.43.5^{\circ} \mathrm{N}\right)$.

in Fig. 13b indicates the recirculation region through the western boundary current. The region that girdles the recirculation region is the ventilated zone where the contour lines emanate from the outcrop line. The important point to be noted is that a contour line, which emanates from the eastern boundary exists east of the ventilated zone. This contour line indicates that seawater, whose potential vorticity was determined at the eastern boundary, intrudes on the interior thermocline. The Bernoulli function contour line emanates from the eastern boundary encloses the south-eastern edge of the subtropical gyre, and around this contour, the easternboundary ventilated zone exists. The potential vorticity
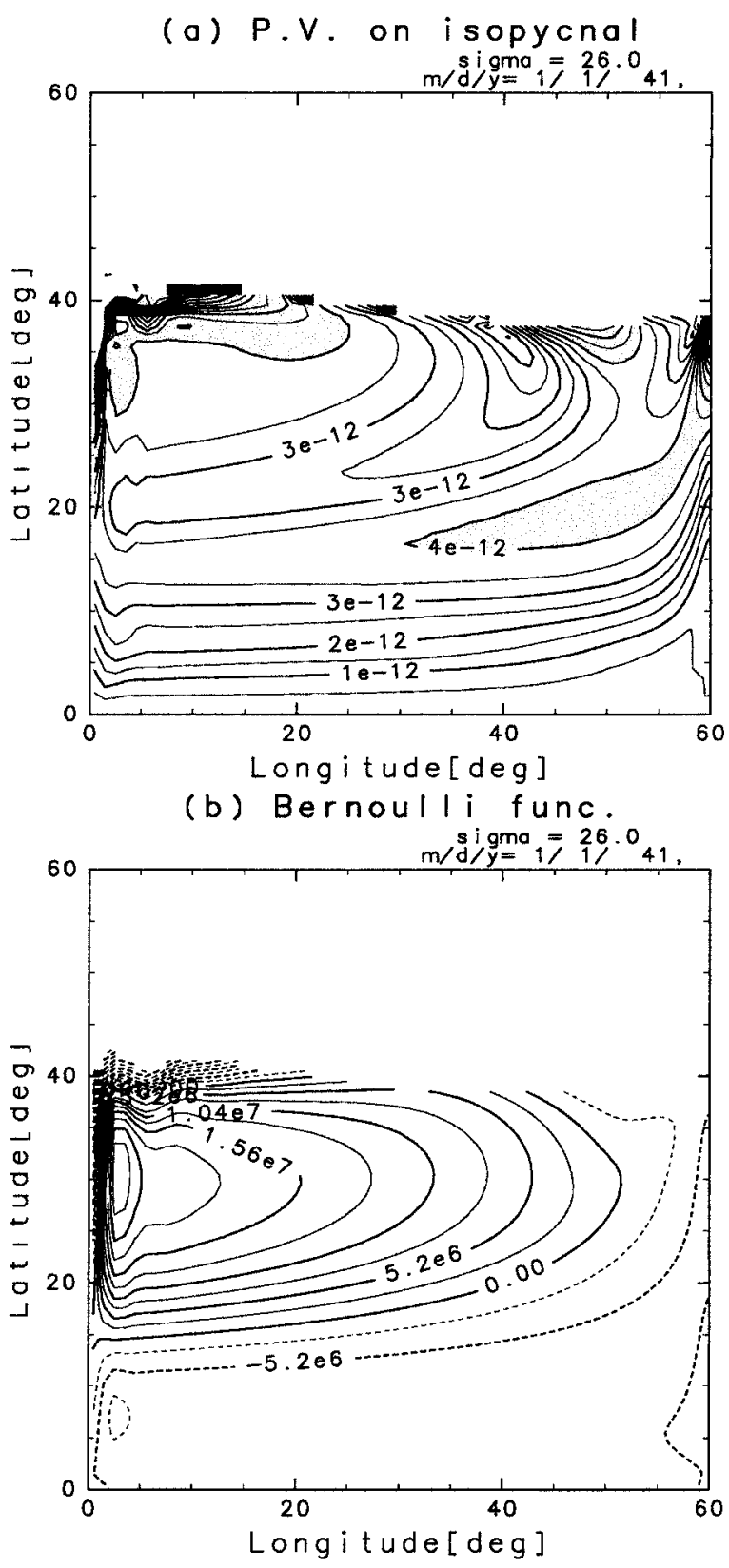

FIG. 13. (a) Potential vorticity on isopycnal surface, $\sigma=26.0$ (run $4)$. Hatched region denotes the high potential vorticity (PV $\geq 4.0 \times$ $10^{-12} \mathrm{~cm}^{-1} \mathrm{~s}^{-1}$ ). (b) Bernoulli function on the same isopycnal surface. Contour line indicates the difference from mean value of $\mathrm{B}$ on this surface. (Units are $\mathrm{g} \mathrm{cm}^{-1} \mathrm{~s}^{-2}$.)

map (Fig. 13a) shows the high potential vorticity tongue that emanates from the eastern boundary extending southwestward. The extension of this high potential vorticity tongue is identified as an intrusion of sea water originated at the eastern boundary. In Figs. 13a and 13b, the shadow zone can be seen in the southeast corner of the subtropics, where the Bernulli function contours are spare.

Colin de Verdière (1989) also showed high PV water 
injection from the eastern boundary. In that paper, boundary injection on the unventilated subtropical thermocline can be clearly seen. Colin de Verdière (1989) mentioned intrusion of the high PV into the LPS's shadow zone, and also discussed that the vertical mixing process is the source of this high PV water.

Except for the western recirculation region, the potential vorticity of sea water in the thermocline is determined by the density structure where the water subducted. Hence the density jump at the eastern boundary acts as a source of high potential vorticity water.

Figures 14 and 15 show the distribution of potential vorticity and the Bernoulli function on $\sigma_{\theta}=26.4$ and $\sigma_{\theta}=27.0$, respectively. The isopycnal surface shown in Fig. 14 outcrops in the vicinity of the IGB, and surface-ventilated region does not exist on this isopycnal. Bernoulli function contour originated from the eastern boundary is also seen. It extends westward along the southern edge of the subtropical gyre and indicates the eastern-boundary ventilated region. The high potential vorticity tongue along this line is clearly seen.

The isopycnal surface shown in Fig. 15 outcrops in the subpolar gyre. In this figure, the Bernoulli function contour line originated from the eastern boundary of the subpolar gyre intersects the IGB and extends southward. This results suggests that the subpolar eastern boundary affects on subtropical deep isopycnals that outcrops in the subpolar gyre through the cross-gyre ventilation of the subtropical gyre (e.g., Pedlosky 1984). On this isopycnal, the flow emanated from the subpolar eastern boundary is so weak that the region of high potential vorticity diffuses and the southward advection is not very clear.

In this section, we showed that the eastern boundary ventilated zone intrudes interior thermocline along the line that divides the surface-ventilated zone and the shadow zone. Therefore, the subtropical gyre can be divided into four regions: the recirculation region, the ventilated region, the eastern boundary ventilated region, and the shadow zone.

\section{Discussion and conclusions}

In this paper, we studied the oceanic eastern boundary structure and its effects on the subtropical interior thermocline by using idealized OGCM. Theoretical ventilated thermocline model with variable depth mixed layer presented by Huang (1990), Huang and Russel (1994), etc., employed an eastern boundary condition that the density below the mixed layer is uniform in the meridional direction. The results of this study support their treatment of the eastern boundary condition. However, serious modification is required about the structure of the isopycnals where the thermocline connects to the bottom of the mixed layer. The results of the numerical experiments show that the eastward flow in the upper part of the mixed layer sinks down and returns to the interior from the lower part of the mixed layer. For such
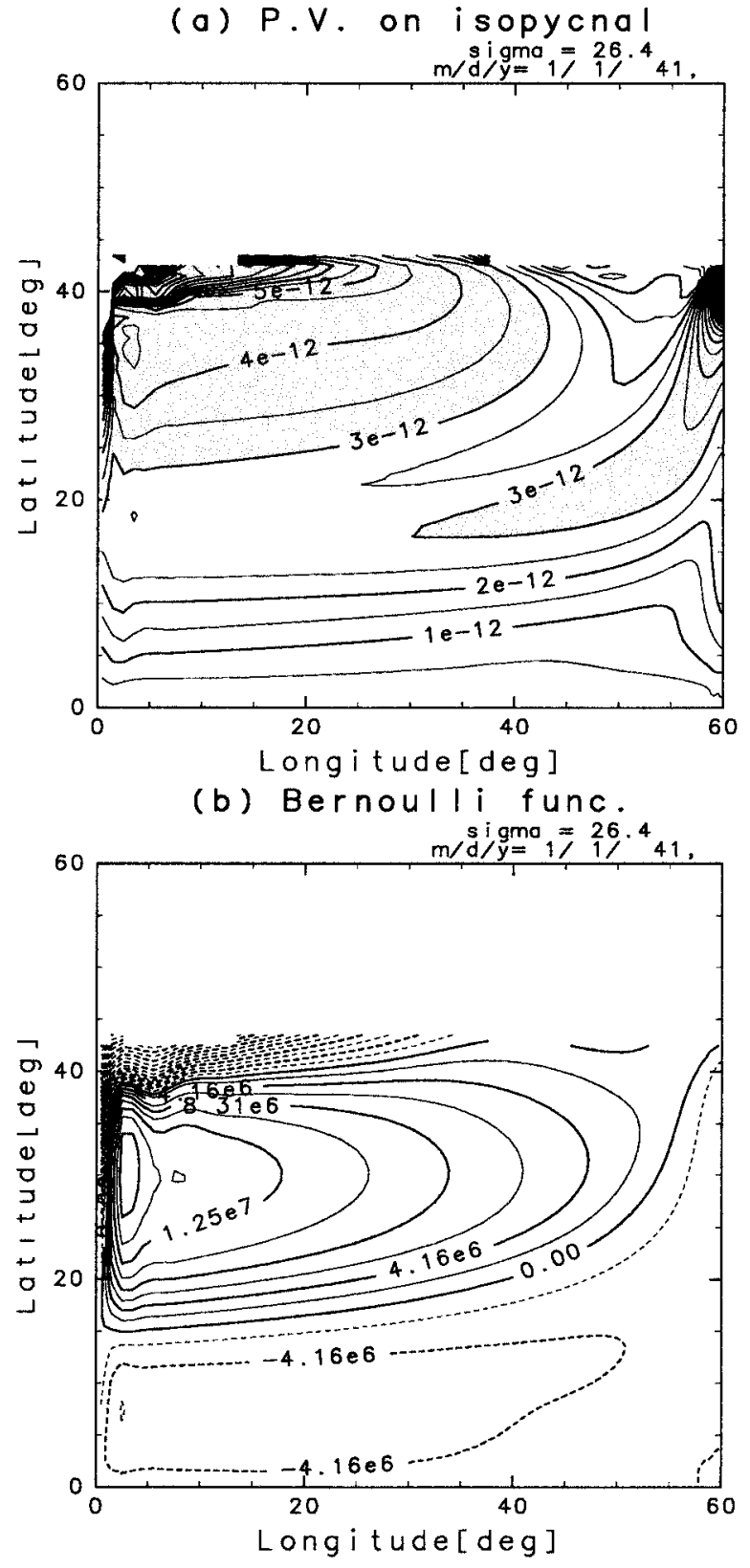

FIG. 14. Same as Fig. 13, but for $\sigma=26.4$. Shaded region in (a) denotes $\mathrm{PV} \geq 3.0 \times 10^{-12} \mathrm{~cm}^{-1} \mathrm{~s}^{-1}$.

zonal velocity in the mixed layer to occur, the isopycnal surface of the thermocline does not smoothly connect to the bottom of the mixed layer, but it deepens steeply once, and then connects to the bottom of the mixed layer. Such structure can also be seen in the eastern boundary of coarse numerical models (e.g., Colin de Verdière 1989; Marotzke 1997). In the limit of weak horizontal diffusion, the density jump must be generated between the bottom of the mixed layer and the thermocline. As shown in appendix A, meridional excursion of the blocked water at the boundary is small in comparison 

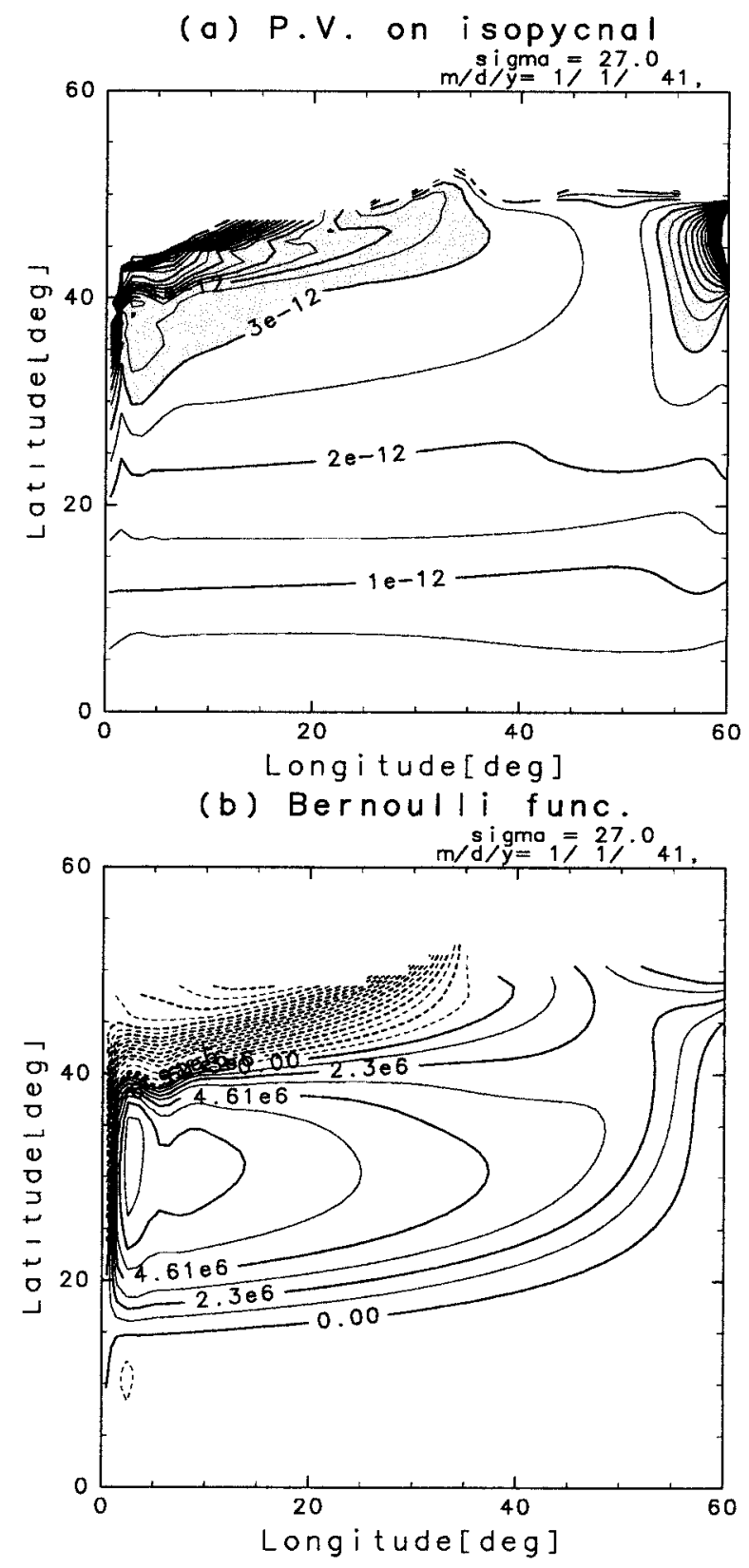

FIG. 15. Same as Fig. 13, but for $\sigma=27.0$. Shaded region in (a) denotes $\mathrm{PV} \geq 3.0 \times 10^{-12} \mathrm{~cm}^{-1} \mathrm{~s}^{-1}$.

with the vertical transport. Therefore, the water hardly changes its density at the eastern boundary and comes back to the interior from almost the same latitude where the flow reached the boundary. This is the reason why the zonal flows are limited in the mixed layer at the eastern boundary. In this way, the no-net-zonal flux condition at the eastern edge of the basin is realized.

Concerning the density structure in the vicinity of the eastern boundary, we present a simple theory by using the condition that the vertically integrated zonal flux must vanish at each latitude on the boundary, and the zonal flow is limited in the mixed layer. As a consequence, we obtained the relationship among the sea surface density, basic stratification along the eastern boundary, and the depth of the mixed layer. This relationship is expressed in Eq. (3.16), and each variable in this equation is not independent any longer. Also it has been shown that the mixed layer depth calculated by the above equation agrees well with the results of the numerical experiments. This implies that the deep mixed layer and the downwelling along the eastern boundary in the GCM are simple consequences from the no-normal-flow condition at the eastern boundary.

Pedlosky (1983) and Huang (1989) considered the eastern boundary condition for the ventilated thermocline model, which satisfies the no-net-zonal flux condition. In those papers, it has been assumed that a boundary layer exists near the eastern edge of the basin in which the vertical transport of the water mass through isopycnal surfaces acts an important role. In contrast to those papers, the result of our study indicates that the vertical transport of the water mass is limited in the mixed layer; therefore, the diapycnal process is not important except in the mixed layer.

It should be noted that in the real ocean, the meridional wind stress $\tau_{\phi}$ is not zero near the eastern boundary. If we take the non zero $\tau_{\phi}$ into consideration, Eq. (3.16) becomes

$$
\frac{1}{2} \frac{\partial z_{m}^{2}}{\partial y}=\frac{1}{\rho_{A}\left(z_{m}\right)-\rho_{s}}\left[\frac{z_{m}^{2}}{2} \frac{\partial \rho_{s}}{\partial y}+\frac{\tau_{\phi}}{g}\right] .
$$

The negative $\tau_{\phi}$ drives the westward Ekman flow, and this Ekman flux reduces the westward flow in the lower half of the mixed layer, resulting in reduction of the mixed layer depth gradient. Since $\tau_{\phi}$ tend to be negative at the eastern boundary in the midlatitude, the mixed layer depth in the idealized OGCM is probably overestimated. In future works, we should examine the mixed layer depth distribution along the eastern boundary using the realistic wind and realistic topography.

We also studied the effects of such eastern boundary structure described above on the subtropical thermocline. As described in Pedlosky (1983) and Huang (1989), the present model also shows that there are four subdomains on isopycnal surfaces outcropping in the subtropical region: unventilated western pool, surfaceventilated region, eastern-boundary ventilated region, and eastern shadow zone. As described in Colin de Verdière (1989), we confirmed that the eastern boundary ventilated region is identified as the high potential vorticity region. The high potential vorticity tongue extending from the eastern boundary can be regarded as the intrusion of the density jump generated at the bottom of the mixed layer. Since the potential vorticity contrast in the ocean interior can strongly affect the ocean circulation structure as discussed by Kubokawa (1999), the high potential vorticity source at the eastern bound- 
ary could also be important in the ocean circulation structure.

It is interesting to note that on the subtropical deep isopycnals outcropping in the subpolar gyre, there is water that originated from the subpolar eastern boundary, which crosses the IGB and flows into the subtropical gyre. The cross-gyre flow is realized by the zonal density structure near the boundary, that is, shallow isopycnals deepening and deep isopycnals shoaling eastward, which is the side view of the density jump along the eastern boundary. The cross-gyre flow near the eastern boundary is generated by the density jump in this way. Accordingly, the subtropical deep isopycnals that outcrop in the subpolar gyre are divided into three regions: the western pool, the cross-gyre ventilated region, and the eastern shadow zone. This fact suggests that the structure of the subtropical deep isopycnals may be deeply influenced by the structure of the subpolar region. In order to further study the effects of the eastern boundary region on the thermocline structure, we should construct the ventilated thermocline model that satisfies the consistent boundary conditions as a next step.

Acknowledgments. The authors thank the two anonymous reviewers for their valuable comments. We also wish to thank T. Inui for her helpful discussions, and M. Nonaka and S. Hosoda for their valuable advice in setting up the model. This work was financially supported by the Japanese Ministry of Education, Science and Culture, Grant-in-Aid for Scientific Research, and by the Grant-in-Aid for the Cooperative Research with the Center for Climate System Research, University of Tokyo. The GFD-DENNOU Library was used for drawing the figures.

\section{APPENDIX A}

\section{Flow Structure beside the Eastern Boundary Wall}

We will describe the flow structure beside the eastern boundary in this appendix. (All figures in appendix A and $B$ are the result of run 1.)

Figure A1a depicts typical zonal distribution of vertically integrated zonal flow near the eastern boundary, the latitude of which is $48.5^{\circ} \mathrm{N}$. In this figure, solid line indicates the integration of the eastward flow in the upper mixed layer, and dashed line indicates the vertical integration of the lower westward flow. We can clearly see that the net zonal mass flux is almost zero near the eastern boundary, and eastward reduction of the zonal flux is limited in very narrow region beside the boundary. If we define $z_{E}$ as the depth at which the direction of zonal flow changes, and integrate the continuity equation from $z_{E}$ to surface, we obtain

$$
\int_{z_{E}}^{0} \frac{\partial u}{\partial x} d z+\int_{z_{E}}^{0} \frac{\partial v}{\partial y} d z=\left.w\right|_{z=z_{E}} .
$$

Figure A1b shows the second term of the left side of
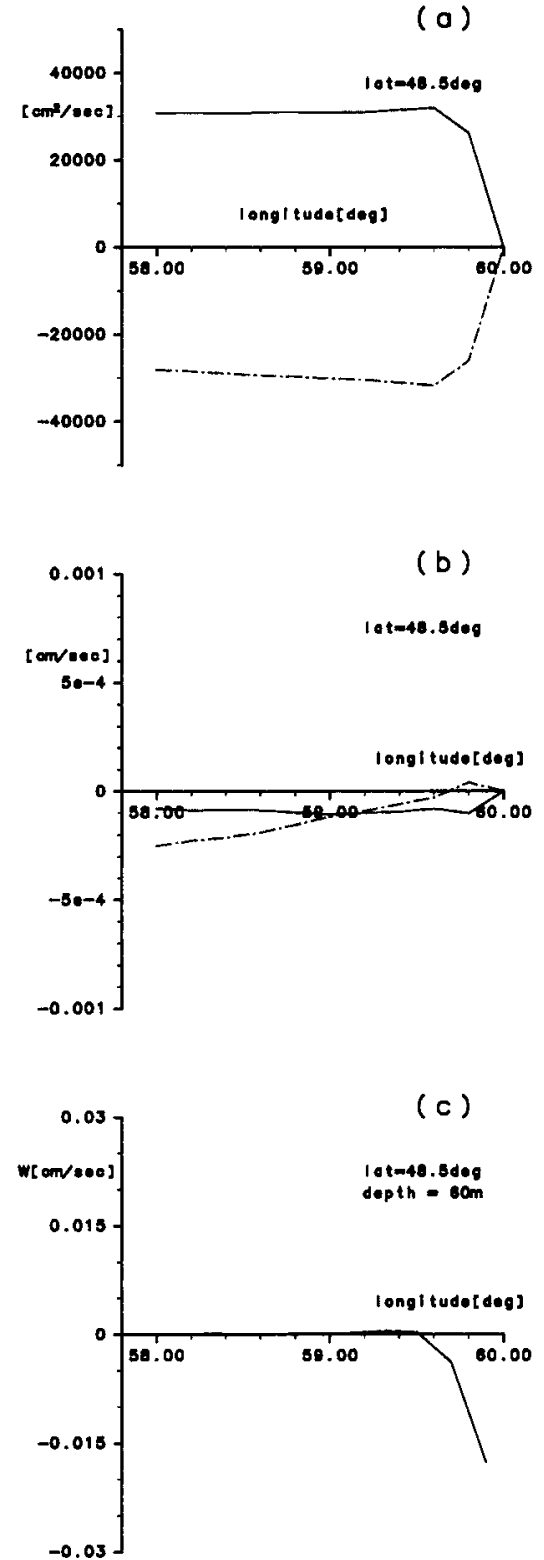

FIG. A1. Flow structure beside the eastern boundary wall of run 1: (a) vertically integrated zonal velocity, solid line indicates upper eastward, and dashed line indicates lower west-ward flow; (b) vertically integrated meridional divergence of $v$ (solid line indicates the upper part, dashed line indicates the lower part); (c) vertical velocity at the depth at which the direction of the zonal flow changes.

the above equation, while Fig. A1c shows the right side. The dashed line in Fig. Alb indicates the same term but integration of beneath $z=z_{E}$. In these figures, it can be clearly seen that the vertical transport is very strong in comparison with the meridional divergence at the boundary. Hence, the most part of the blocked eastward flow change its direction to downward at the boundary, and return to the interior region from the lower part. 


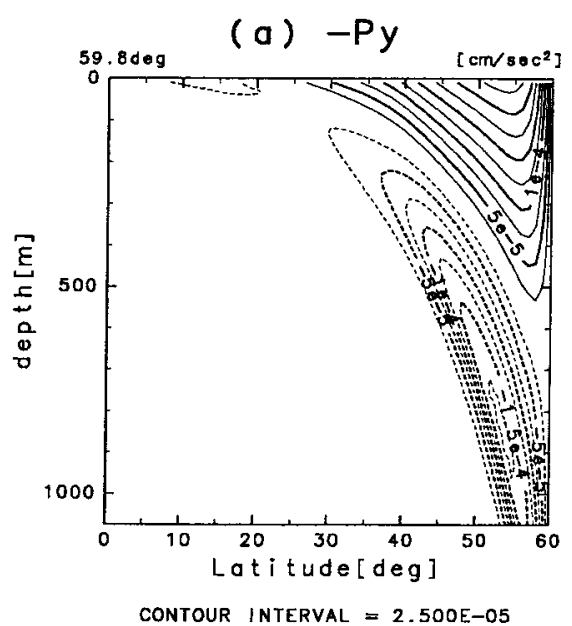

(c) $V z z$

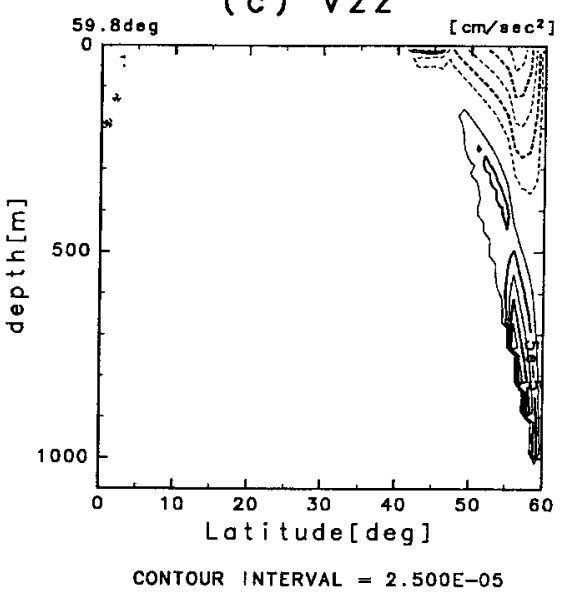

(b) fU

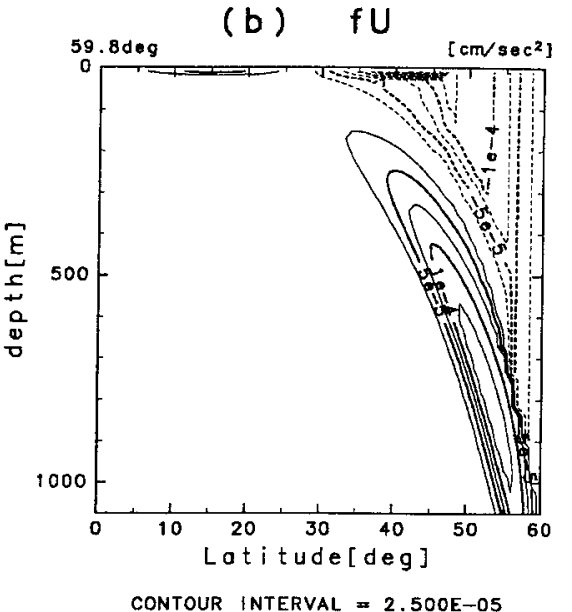

CONTOUR INTERVAL $=2.500 \mathrm{E}-05$

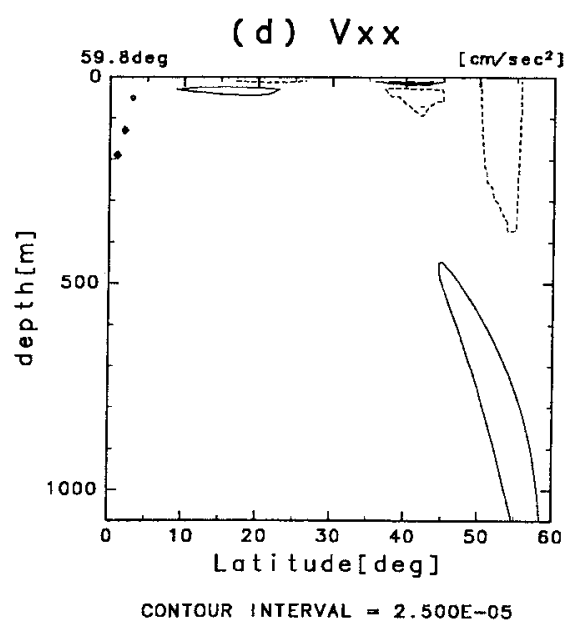

FIG. B1. Dominant terms in the meridional momentum equation at the most eastern grid of run 1: (a) pressure gradient, (b) Coriolis term, (c) vertical viscosity, (d) horizontal (zonal) viscosity.

\section{APPENDIX B}

\section{Momentum Balance along the Eastern Side Wall}

Concerning the meridional density structure, we already showed that the geostrophic balance provides good approximation $1^{\circ}$ apart from the eastern boundary. In this appendix, we will see the momentum balance along the eastern side wall.

In our numerical experiments, the MOM code uses a so-called B-grid system. Therefore the most eastern grid ( $u, v$ point) where the model solves the momentum equation is $59.8^{\circ}$. Figure B1 depicts the meridional momentum balance of run 1 , in the meridional section at $59.8^{\circ}$, in which only the dominant terms are displayed. Figures B1a-d indicate the pressure gradient term, Coriolis term, vertical viscosity, and horizontal (zonal) viscosity, respectively. Other terms are much smaller than them. Figures B1a and B1b indicate that the balance between the pressure gradient and Coriolis term is very important, while Fig. B1c and B1d indicate that the vertical and horizontal viscosity concerns with the meridional velocity become the same order value and affect the above balance, which indicates that the density structure along the eastern side wall cannot be held by the pure geostrophic balance. Considering the pressure gradient term shown in Fig. B1a the water mass in the mixed layer tends to move northward in the upper part, and southward in the lower part. The distribution of vertical viscosity term in Fig. B1c can be interpreted as the effect of second-order vertical differential of such counterflowing water mass. As previously mentioned, the convective adjustment occurs very frequently in the upper part of the mixed layer, which makes effect of the vertical viscosity large.

Figure B2 depicts terms of zonal momentum equation in the same section as in Fig. B1. Similar to Fig. B1, Figs. B2a-d indicate the pressure gradient term, Coriolis term, vertical viscosity, and horizontal viscosity, respectively. Other terms are much smaller than them. These figures show that the geostrophy is the major balance on this section, while the horizontal viscosity term in Fig. B2d becomes the same order as the pressure 

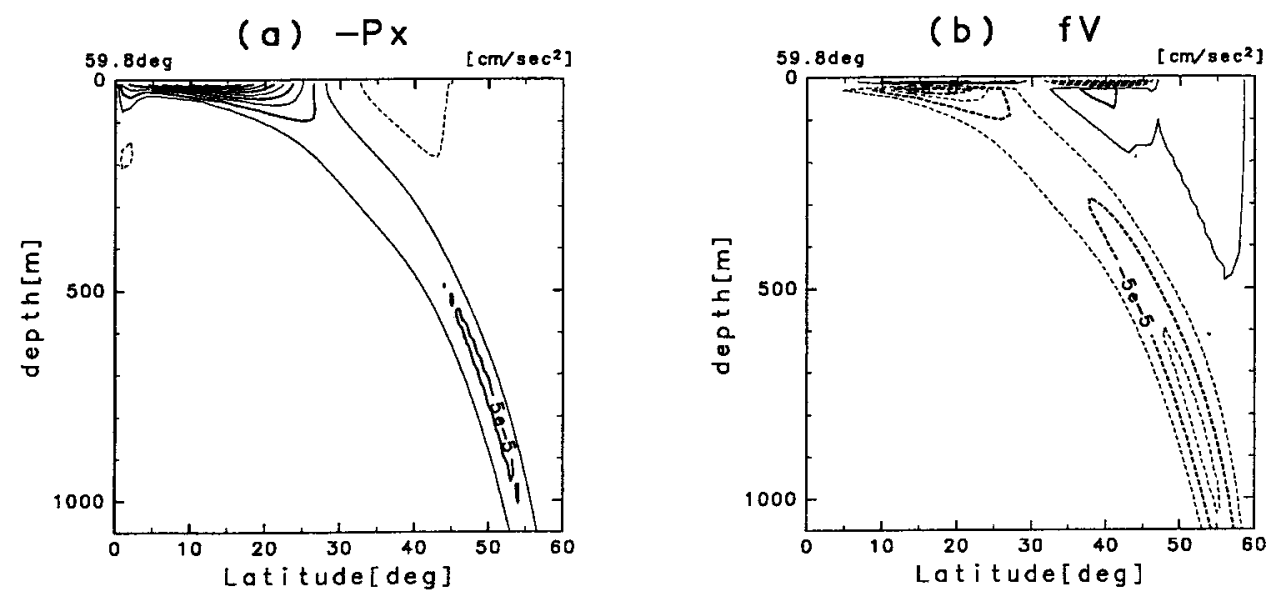

CONTOUR INTERVAL $=2.500 E-05$
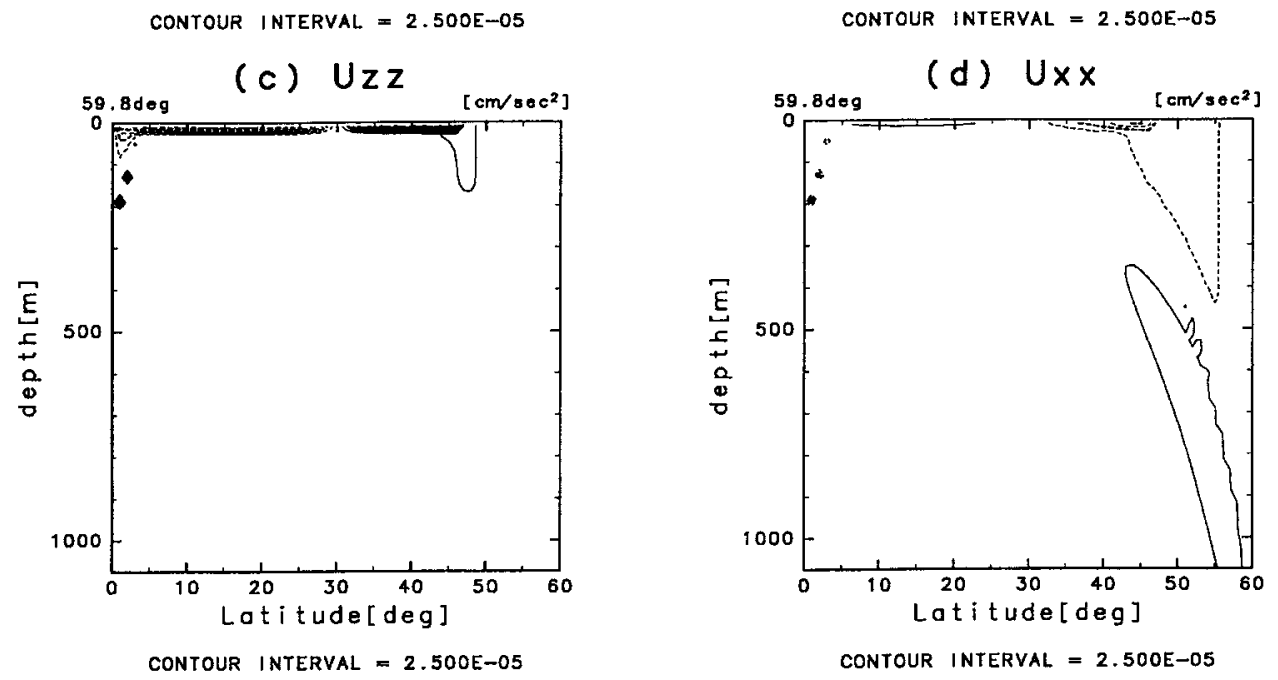

FIG. B2. Same as Fig. B1, but for zonal momentum equation.

gradient and Coriolis term. This is because the rapid reduction of zonal velocity at the eastern side wall. The vertical viscosity term is large at the surface and balances with the Coriolis term at the surface. It should be noted here that the Coriolis term in Fig. B2b indicates that the meridional velocity is $O\left(10^{-1}\right) \mathrm{cm} \mathrm{s}^{-1}$ in this section. Therefore, the meridional advection of water mass along the side wall is limited in short distance, and then the water mass hardly changes its density before it comes back to the interior.
Although the geostrophic balance does not hold near the boundary, the Coriolis term is still dominant in the present model, suggesting that the eastern boundary layer is not perfectly resolved. Therefore, there remains some uncertainty concerning the eastern boundary layer's structure. To remove the uncertainty, we carried out additional experiment, in which the grid spacing near the eastern side wall is $0.04^{\circ}$ and the other configuration of the model is the same as run 1 ; the zonal grid spacing of this additional experiment is shown in Fig. B3. This

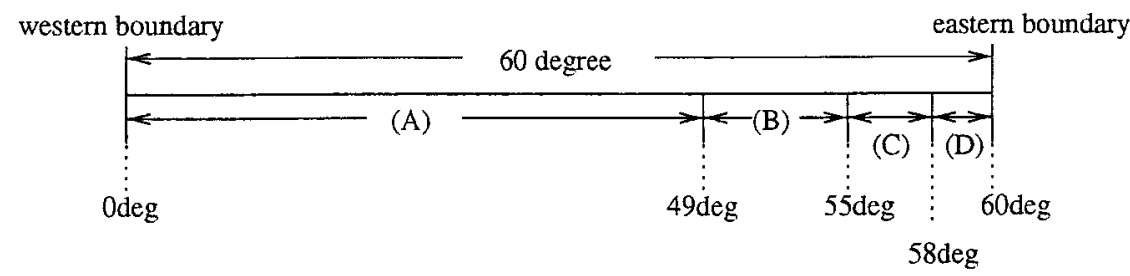

FIG. B3. Zonal grid spacing of additional experiment. Longitudinal widths of grids are uniform $1^{\circ}$ in region $\mathrm{A}$, gradually reduce from $1^{\circ}$ to $0.2^{\circ}$ in region $\mathrm{B}$, gradually reduce from $0.2^{\circ}$ to $0.04^{\circ}$ in region $\mathrm{C}$, and uniform $0.04^{\circ}$ in region. 


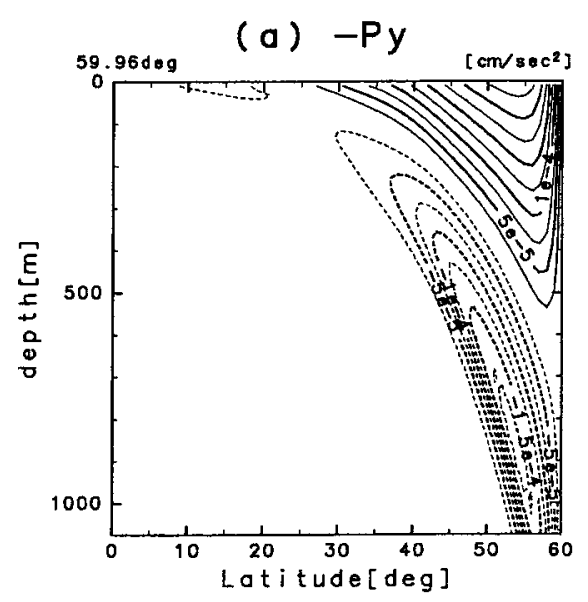

CONTOUR INTERVAL $=2.500 E-05$

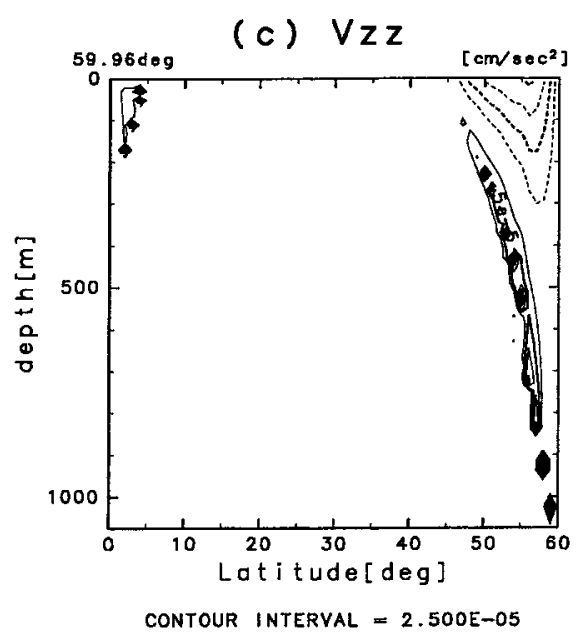

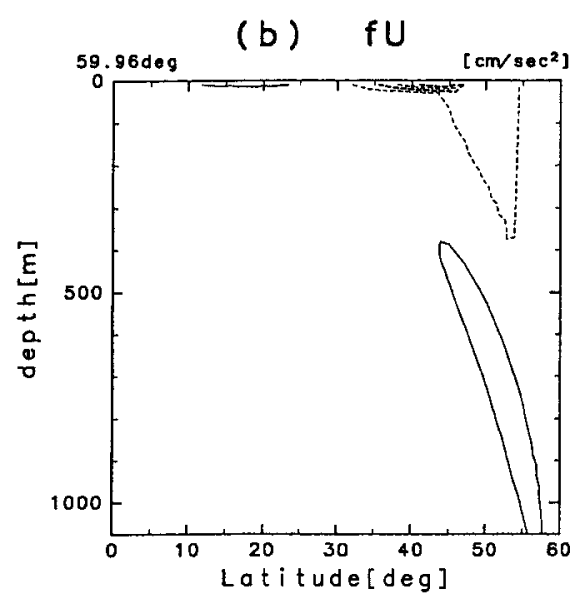

CONTOUR INTERVAL $=2.500 E-05$

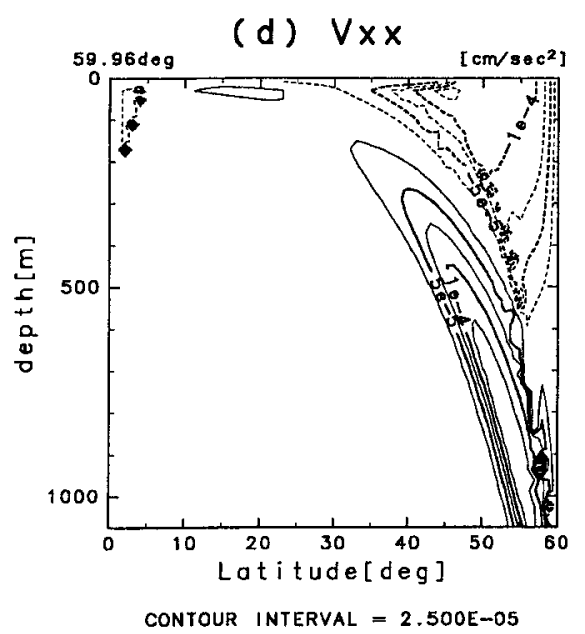

FIG. B4. Same as Fig. B1, but for additional experiment.

change in the grid spacing did not affect the current profile and density structure at $59^{\circ}$ and overall structure of the ocean circulation at all.

Figure B4 depicts the meridional momentum balance of additional experiment at the most eastern meridional section $\left(59.96^{\circ}\right)$. Similar to Fig. B1, only the dominant terms are displayed: the pressure gradient term (Fig. B4a), Coriolis term (Fig. B4b), vertical viscosity (Fig. B4c), and horizontal (zonal) viscosity (Fig. B4d). Other terms are much smaller than these. Figure B4a shows the pressure gradient term-in other words, the density structure along the side wall-is the same shape as run 1, while Fig. B4b indicates that the zonal velocity at is very small and Coriolis term does not affect the momentum term balance in this section any longer. Instead of Coriolis term, the zonal viscosity term due to the rapid reduction of meridional velocity at the boundary becomes the dominant term (Fig. B4d). In this way, the density structure beside the eastern side wall is maintained in the same shape as in the section: $1^{\circ}$ apart from the boundary.

Above results suggest that the no-slip condition of the model acts an important role to maintain the density structure beside the wall. It should be noted here that the free slip condition may need another mechanism to maintain the boundary structure.

\section{REFERENCES}

Arhan, M., A. Colin de Verdière, and L. Mémery, 1994: The eastern boundary of the sub-tropical North Atlantic. J. Phys. Oceanogr., 24, 1295-1316.

Bryan, K., 1969: A numerical method for the study of the circulation of the World Ocean. J. Comput. Phys., 4, 347-376.

Colin de Verdière, A., 1989: On the interaction of wind and buoyancy driven gyres. J. Mar. Res., 47, 595-633.

Cox, M. D., and K. Bryan, 1984: A numerical model of the ventilated thermocline. J. Phys. Oceanogr., 14, 674-687.

de Szoeke, R. A., 1992: Effects of alongshore wind stress at the eastern boundary on circulation in the ocean pycnocline. J. Phys. Oceanogr., 22, 247-267.

Gill, A. E., 1982: Atmosphere-Ocean Dynamics. International Geophysics Series, Vol. 30, Academic Press, 662 pp.

Haney, R. L., 1971: Surface thermal boundary condition for ocean circulation models. J. Phys. Oceanogr., 1, 241-248.

Hellerman, S., and M. Rosenstein, 1983: Normal monthly wind stress 
over the world ocean with error estimates. J. Phys. Oceanogr. 13, 1093-1104.

Huang, R. X., 1988: On boundary value problems of the ideal fluid thermocline. J. Phys. Oceanogr., 18, 619-641.

— 1989: The generalized eastern boundary conditions and the three-dimensional structure of the ideal fluid thermocline. $J$. Geophys. Res., 94, 4855-4865.

_ 1990: On the three-dimensional structure of wind-driven circulation in the North Atlantic. Dyn. Atmos. Oceans., 15, 117159.

— cific. J. Phys. Oceanogr., 24, 2589-2605.

Huck, T., A. J. Weaver, and A. Colin de Verdière, 1999: On the influence of the parameterization of lateral boundary layers on the thermohaline circulation in coarse-resolution models. J. Mar. Res., 57, 387-426.

Kubokawa, A., 1999: Ventilated thermocline strongly affected by a deep mixed-layer: A theory for subtropical countercurrent. $J$. Phys. Oceanogr., 29, 1324-1333.

Levitus, S., 1982: Climatological Atlas of the World Ocean. NOAA Professional Paper 13, 173 pp.
Luyten, J., J. Pedlosky, and H. Stommel, 1983: The ventilated thermocline. J. Phys. Oceanogr., 13, 292-309.

Marotzke, J., 1997: Boundary mixing and the dynamics of threedimensional thermohaline circulation. J. Phys. Oceanogr., 27, 1713-1728

Paillet, J., and M. Arhan, 1996: Oceanic ventilation in the eastern North Atlantic. J. Phys. Oceanogr., 26, 2036-2052.

Pedlosky, J., 1983: Eastern boundary ventilation and the structure of the thermocline. J. Phys. Oceanogr., 13, 2038-2044.

_, 1984: Cross-gyre ventilation of the subtropical gyre: An internal mode in the ventilated thermocline. J. Phys. Oceanogr. 14, 1172-1178.

- and P. Robbin, 1991: The role of the finite mixed-layer thickness in the structure of the ventilated thermocline. J. Phys. Oceanogr. 21, 1018-1031.

Rhines, P. B., and W. R. Young, 1982: A theory of the wind-driven circulation. I. Mid-ocean gyres. J. Mar. Res., 40 (Suppl.), 559596.

Talley, L. D., 1985: Ventilation of the subtropical North Pacific: The shallow salinity minimum. J. Phys. Oceanogr., 15, 633-649.

UNESCO, 1981: Tenth report of the joint panel on oceanographic tables and standards. UNESCO Tech. Papers in Marine Science No. 36, 25 pp. 